\title{
AVALIAÇÃO DE SIMULAÇÃO HISTÓRICA DA PRECIPITAÇÃO E TEMPERATURA NA AMAZÔNIA ORIENTAL UTILIZANDO UM MODELO DE ALTA RESOLUÇÃO
}

\author{
COSTA, Claudia Priscila Wanzeler da - claudia.costa@itv.org \\ Instituto Tecnológico Vale - ITV \\ SOUZA, Everaldo Barreiros de - everaldo@ufpa.br \\ Universidade Federal do Pará - UFPA \\ ALVES, Lincoln Muniz - lincoln.alves@inpe.br \\ Instituto Nacional de Pesquisas Espaciais - INPE \\ MEIRA FILHO, Luiz Gylvan - Igylvan@uol.com.br \\ Universidade de São Paulo - USP
}

SILVA FERREIRA, Douglas Batista - douglas.silva.ferreira@itv.org Instituto Tecnológico Vale - ITV
KUHN, Paulo Afonso Fisher - pkuhn@ufpa.br Universidade Federal do Pará - UFPA

FRANCO, Vânia dos Santos - vsanfranco@yahoo.com.br

Programa de Pós-Graduação em Ciências Ambientais / Universidade Federal do Pará - UFPA
OLIVEIRA, Juarez Ventura de - juarez.oliveira@pq.itv.org Instituto Tecnológico Vale - ITV

SODRÉ, Giordani Rafael Conceição - giordani@ufpa.br Universidade Federal do Pará - UFPA

\begin{abstract}
RESUMO: Este estudo apresenta avaliação do sistema de modelagem climática regional PRECIS (Providing Regional Climate for Impacts Studies) em simular o clima atual (25 anos, 1981-2005) sobre a Amazônia oriental. As saídas do modelo global HadGEM2-ES foram utilizadas como condições de contorno para o modelo regional dentro do PRECIS, o HadRM3P. Os dados consistiram de médias mensais de precipitação $\left(\mathrm{mm}^{\mathrm{d}} \mathrm{dia}{ }^{-1}\right)$ e temperatura do ar $\left({ }^{\circ} \mathrm{C} \cdot \mathrm{dia}^{-1}\right)$, a partir das quais obteve-se as médias sazonais. Para a avaliação com as simulações fez-se o uso de observações provenientes do CPC (Climate Prediction Centre) e do CRU (Climate Research Unit). O desempenho do modelo foi avaliado através de análises de índices estatísticos como o viés, Raiz do Erro Médio Quadrático (REMQ), coeficiente de correlação, média e desvio padrão. Os resultados mostraram que o PRECIS reproduz razoavelmente bem os padrões espaciais sazonais da precipitação e temperatura na área de estudo, porém apresenta erros sistemáticos provenientes do HadGEM2-ES, principalmente em DJF (Dezembro-Janeiro-Fevereiro) e MAM (Março-Abril-Maio) no norte (em relação à precipitação) e no leste (à temperatura) da região, respectivamente. Todavia, representou bem a variabilidade temporal da precipitação na porção sul da região, principalmente em MAM, e da temperatura em JJA (Julho-Agosto-Setembro). Os escores estatísticos entre as séries de dados simulados e observados das regiões homogêneas na Amazônia oriental revelaram que o HadRM3P tem melhor acurácia em simular a precipitação em JJA, enquanto a temperatura é melhor representada em SON (Setembro-Outubro-Novembro). Em relação ao ciclo anual nas regiões homogêneas, o modelo regional apresentou melhor desempenho que o global em
\end{abstract}


reproduzir a precipitação, principalmente na estação seca, no entanto, tanto o modelo global quanto o modelo regional tendem a acentuar o ciclo anual da temperatura

Palavras-Chave: Dowscaling dinâmico; PRECIS; Avaliação do modelo climático; HadGEM2-ES; Amazônia oriental

\section{HISTORICAL SIMULATION EVALUATION OF PRECIPITATION AND TEMPERATURE IN EASTERN AMAZONIA USING A HIGH RESOLUTION MODEL}

ABSTRACT: This study presents an assessment of the regional climate modeling system PRECIS (Providing Regional Climate for Impacts Studies) in simulating the current climate (25 years, 1981-2005) on the eastern Amazon. The HadGEM2-ES global model outputs were used as boundary conditions for the regional model within PRECIS, HadRM3P. The data consisted of monthly averages of precipitation (mm.day ${ }^{-1}$ ) and air temperature $\left({ }^{\circ} \mathrm{C}\right.$.day- 1$)$, from which the seasonal means were obtained. The simulations were evaluated with observations from the CPC (Climate Prediction Center) and the CRU (Climate Research Unit). The performance of the model was evaluated through statistical index analyzes such as bias, root mean square error (RMSE), correlation coefficient, mean and standard deviation. The results showed that PRECIS reproduces reasonably well the seasonal spatial patterns of precipitation and temperature in the study area, but presents systematic errors from HadGEM2-ES, mainly in DJF (December-JanuaryFebruary) and MAM (March-April-May) in the north (in relation to precipitation) and in the east (at the temperature) of the region, respectively. However, it represented well the temporal variability of the precipitation in the southern portion of the region, mainly in MAM, and the temperature in JJA (July-August-September). Statistical scores between the simulated and observed data series from the homogeneous regions in the eastern Amazon revealed that the HadRM3P has a better accuracy in simulating precipitation in $\mathrm{JJA}$, while at temperature, it is better represented in SON (September-OctoberNovember). Regarding the annual cycle in the homogeneous regions, the regional model presented a better performance than the global one in reproducing precipitation, particularly in the dry season, however, both models, global and the regional, tend to accentuate the annual temperature cycle.

Keywords: Dynamical downscaling; PRECIS; Assessment of climate model; HadGEM2ES; Eastern Amazon

\section{INTRODUÇÃO}

A Amazônia brasileira abrange um território de aproximadamente 5 milhões de $\mathrm{km}^{2}$ de extensão e possui uma rica biodiversidade de fauna e flora. Em sua porção oriental, realizam-se importantes atividades que contribuem para o desenvolvimento e economia do País, como a agricultura, geração de energia, pecuária, extrativismo mineral entre outras. Estas, por sua vez, são frequentemente expostas às intempéries do tempo e do clima. No contexto climático, a precipitação, nesta região, apresenta grande variabilidade espacial e temporal (FIGUEROA E NOBRE, 1990; MARENGO E ESPINOZA, 2015), onde os maiores volumes anuais são observados no verão e outono austrais (MARENGO et al., 2001) relacionados aos padrões de circulação de grande escala como a Zona de Convergência do Atlântico Sul (ZCAS) Zona de Convergência Intertropical (ZCIT) (DE SOUZA E ROCHA, 2006; DE SOUZA et al., 2009), e de mesoescala como Sistemas Convectivos de Mesoescala (SCM) (GRECO et al., 1990; SILVA DIAS et al., 2009), particularmente na forma de Linhas de Instabilidade que se originam na costa norte da região Amazônica (COHEN et al., 1995).

Quanto à temperatura, de acordo com Marengo e Nobre (2009), sobre esta região incidem altos valores de energia solar que ocasionam pequenas 
variações ao longo do ano, exceto na porção sul da Amazônia (estados de Rondônia e Mato Grosso), que sofre a ação de sistemas frontais que influenciam o tempo nesta região ocasionando quedas significativas na temperatura do ar (friagens) (BRINKMAN E RIBEIRO, 1972; OLIVEIRA et al., 2004; AMORIN NETO, 2013; RICARTE et al., 2015). Em termos sazonais, as médias variam entre $24^{\circ}$ e $26^{\circ} \mathrm{C}$ e são observadas a amplitude térmicas de $1^{\circ}$ a $2^{\circ} \mathrm{C}$ (MARENGO $\mathrm{E}$ NOBRE, 2009)

O entendimento do clima e de sua variabilidade pode reduzir os impactos negativos causados direta ou indiretamente às atividades humanas e ambientais. Todavia, a carência de dados observacionais, bem como a falta de uma extensa rede de observações meteorológicas dificultam a produção de análises climatológicas de alta resolução temporal (DE SOUZA CUSTÓDIO et al., 2016). Por esse motivo, os Modelos Climáticos Globais (MCGs) tornaram-se importantes ferramentas no estudo da variabilidade e mudança do clima (MEEHL et al., 2007). Suas equações internas representam os processos físicos que ocorrem no sistema climático, o qual é formado pela atmosfera, oceanos, biosferas terrestres e marinhas, criosfera (regiões cobertas por gelo) e pela superfície terrestre (AMBRIZZI et al., 2007). Esses componentes interagem entre si e através dessa interação coletiva determinam o clima da Terra.

Os MCGs têm tido grandes avanços nos últimos anos em termos de representação de processos (físicos e dinâmicos, porém, em geral, ainda possuem resolução horizontal de centenas de quilômetros, o que os torna não aplicáveis para se estudar o clima regional (MENDES E MARENGO, 2009; TIMBAL et al., 2009) ainda que, forneçam simulações adequadas da circulação atmosférica em escala global (CAMARGO et al., 2001; CAVALCANTI et al., 2002; MARENGO et al., 2003). Deste modo, o desenvolvimento de técnicas de transferência da informação gerada pelos MCGs em larga escala para escalas menores, isto é, as chamadas técnicas de "downscaling dinâmico" utilizando Modelos Climáticos Regionais (MCR) que permitem um maior detalhamento espacial e temporal das variáveis do sistema climático em relação aos MCGs (WEICHERT E BURGER,1998; SALATHÉ, 2003; MENDES E MARENGO, 2009; TIMBAL et al., 2009), tornam-se uma ferramenta útil para estudar as mudanças e flutuações climáticas em escala regional. Uma revisão comparando os vários métodos de downscaling aplicados à saída dos MCGs é vista em Wilby e Wigley (1997) e Giorgi et al. (2001). Basicamente, as saídas dos modelos globais, com baixa resolução, são utilizadas como condições de contorno para o modelo regional que realiza as simulações em alta resolução ( 25 a 50km), proporcionando assim, uma representação mais realística do clima, onde fatores locais como a topografia acentuada (ex. montanhas), a proximidade com o oceano, cobertura superficial heterogênea sejam capturados pelos modelos regionais (DE SOUZA et al., 2016). As desvantagens da modelagem climática regional são os custos computacionais e a incapacidade de remover explicitamente as diferenças sistemáticas ou vieses entre os modelos globais e observações (SALATHÉ et al., 2008).

O PRECIS é um sistema de modelagem climática regional, desenvolvido pelo Met Office Hadley Centre, e foi concebido para ser executado em um computador pessoal (PC, sigla em inglês) com sistema Linux. A principal motivação, que levou sua construção, foi possibilitar que países em desenvolvimento produzam seus próprios cenários regionais em estudos de impactos da mudança do clima (JONES et al., 2004), utilizando uma 
infraestrutura de baixo custo computacional. Por esse motivo, o PRECIS tem sido amplamente utilizado em estudos de clima regional no mundo, como no China (ZHANG et al. 2006), sul da África (HEWITSON E CRANE, 2006), norte da Índia (MATHISON et al., 2013), oeste dos Estados Unidos (LI et al, 2015), na Malásia (LOH et al., 2016), entre outros.

O PRECIS também foi aplicado em estudos de clima regional sobre a América do Sul, como descrito no estudo de Alves e Marengo (2010), que avaliaram a acurácia do HadRM3P, modelo regional do PRECIS, a uma resolução de $50 \mathrm{~km}$, aninhado ao modelo global HadAM3P, em descrever a variabilidade sazonal da precipitação, temperatura e circulação em baixos e altos níveis sobre a América do Sul e oceanos adjacentes, no período de 1961 a 1990. De forma geral, seus os resultados revelaram com detalhes que os principais padrões climatológicos dessas variáveis foram melhor capturados pelo modelo regional que pelo modelo global. No entanto, apresentou erros sistemáticos negativos (subestimativa) na temperatura em áreas tropicais e na precipitação na parte central do continente durante a estação chuvosa e erros de menor magnitude nesta mesma região durante a estação seca.

Tanajura et al. (2010) realizaram simulações para o clima presente, considerando o período de 1961 a 1990) sobre o Estado da Bahia utilizando o HadRM3P, com resolução de $50 \mathrm{~km}$, aninhado ao modelo global HadAM3 e comparou com observações proveniente de INMET. Os resultados mostraram que o modelo foi capaz de simular os principais padrões do ciclo sazonal de precipitação, temperatura e umidade relativa a $2 \mathrm{~m}$ em quase todo o Estado da Bahia. No entanto, a magnitude da precipitação, ao longo do litoral, foi menor do que a observada, e o modelo não produziu nenhuma precipitação no semiárido e oeste da Bahia durante os meses de junho-julho-agosto, impondo um cenário climático mais drástico que o observado.

Apesar das várias aplicações do PRECIS no mundo, ainda são poucos os trabalhos que focam na Amazônia, mais particularmente no seu lado oriental, onde os modelos numéricos apresentam dificuldades em simular o clima, em parte podendo ser explicado por suas inadequadas parametrizações para região como a parametrização de convecção (ADAMS et al., 2009).

Diante do exposto, o presente trabalho visa contribuir com estudos de modelagem climática sobre a Amazônia oriental, avaliando o modelo climático regional (HadRM3P) aninhado ao modelo global (HadGEM2-ES). Para tanto, almejou-se quantificar a destreza do HadRM3P em representar o clima atual (1981 - 2005), bem como, identificar os aspectos críticos (erros sistemáticos) da simulação climática regional na Amazônia oriental, e assim sugerir, se necessário, melhorias nas parametrizações do modelo, a fim de se obter projeções de clima futuro com maior confiabilidade.

\section{MATERIAL E MÉTODOS}

\subsection{DADOS OBSERVACIONAIS}

Para avaliação das simulações e caracterizações dos principais padrões atmosféricos dominantes sobre a Amazônia foram utilizados dados:

a) Precipitação diária $(\mathrm{mm})$ proveniente do Climate Prediction Center (CPC, CHEN et al, 2008). Este conjunto de dados é baseado principalmente em dados de precipitação observada que são interpolados pelo método de 
Interpolação Ótima (GANDIM, 1965), podendo ser obtidos: $\mathrm{ftp}: / /$ ftp.cpc.ncep.noaa.gov/precip/CPC_UNI_PRCP/GAUGE_GLB/. Este método é aplicado a partir de informações de 30000 pluviômetros na versão retrospectiva (1979-2005) e 17000 na versão em tempo real (2006 até o presente), obtendo-se uma cobertura global de dados sobre a superfície, com resolução espacial de $0,5^{\circ} \times 0,5^{\circ}$ de latitude/longitude. A partir dos dados originais foram calculadas as médias mensais e sazonais da precipitação para a Amazônia oriental.

b) Temperatura do ar (K) mensal proveniente do Climate Research Unit (CRU) Time-series versão 4.00 (TS4.00) da University of East Anglia. Os dados são baseados nas análises de mais de 4000 registros de estações meteorológicas abrangendo toda a área continental (HARRIS et al., 2014). Para esta nova versão, os dados são disponibilizados no período de 1901 a 2015 na resolução espacial de $0,5^{\circ} \times 0,5^{\circ}$ de latitude/longitude, e difere-se da versão anterior apenas na metodologia utilizada para interpolar os dados das estações. Maiores informações sobre estes dados bem como seu acesso podem ser obtidos no link abaixo, http://data.ceda.ac.uk/badc/cru/data/cru_ts/cru_ts_4.00/. As médias sazonais da temperatura do ar foram obtidas a partir dos dados originais mensais.

\subsection{DESCRIÇÃO DO MODELO E CONFIGURAÇÃO DO EXPERIMENTO}

Para a regionalização foi utilizado o sistema de modelagem PRECIS (Providing Regional Climates for Impacts Studies) versão 2.0 desenvolvido pelo Met Office Hadley Centre (JONES et al., 2004), na resolução horizontal de $0.22^{\circ}$ de lat/long $(\sim 25 \mathrm{~km})$. O PRECIS consiste de um Modelo Climático Regional (MCR), o HadRM3P, que utiliza as condições atmosféricas e oceânicas de grande escala a partir de observações ou de Modelos de Circulação Global (MCG), onde as resoluções horizontais variam de 100 a $300 \mathrm{~km}$, e reduz a escala para uma região de interesse com resoluções de 25 ou $50 \mathrm{~km}$, permitindo assim, uma representação mais realística do clima regional. A escolha pelo uso do PRECIS se dá por este possuir uma interface de usuário simplificada, podendo ser rodado sobre qualquer área no mundo com um pequeno custo computacional.

O HadRM3P está acoplado aos esquemas de superfície MOSES 2.2 (Met Office Surface Exchange), no entanto, as temperaturas de superfície, fluxos radiativos de ondas curtas e longas, fluxos de calor sensível, fluxos de calor no solo, teor de umidade no dossel e taxas de derretimento da neve são calculados para cada tipo de superfície em uma caixa de grade (Technical Manual for PRECIS). A tabela 1 contém as principais características do modelo regional no PRECIS 2.0. 
Tabela 1 - Principais características do modelo regional HadRM3P no PRECIS 2.0 utilizado neste estudo. Adaptado de Alves, 2007.

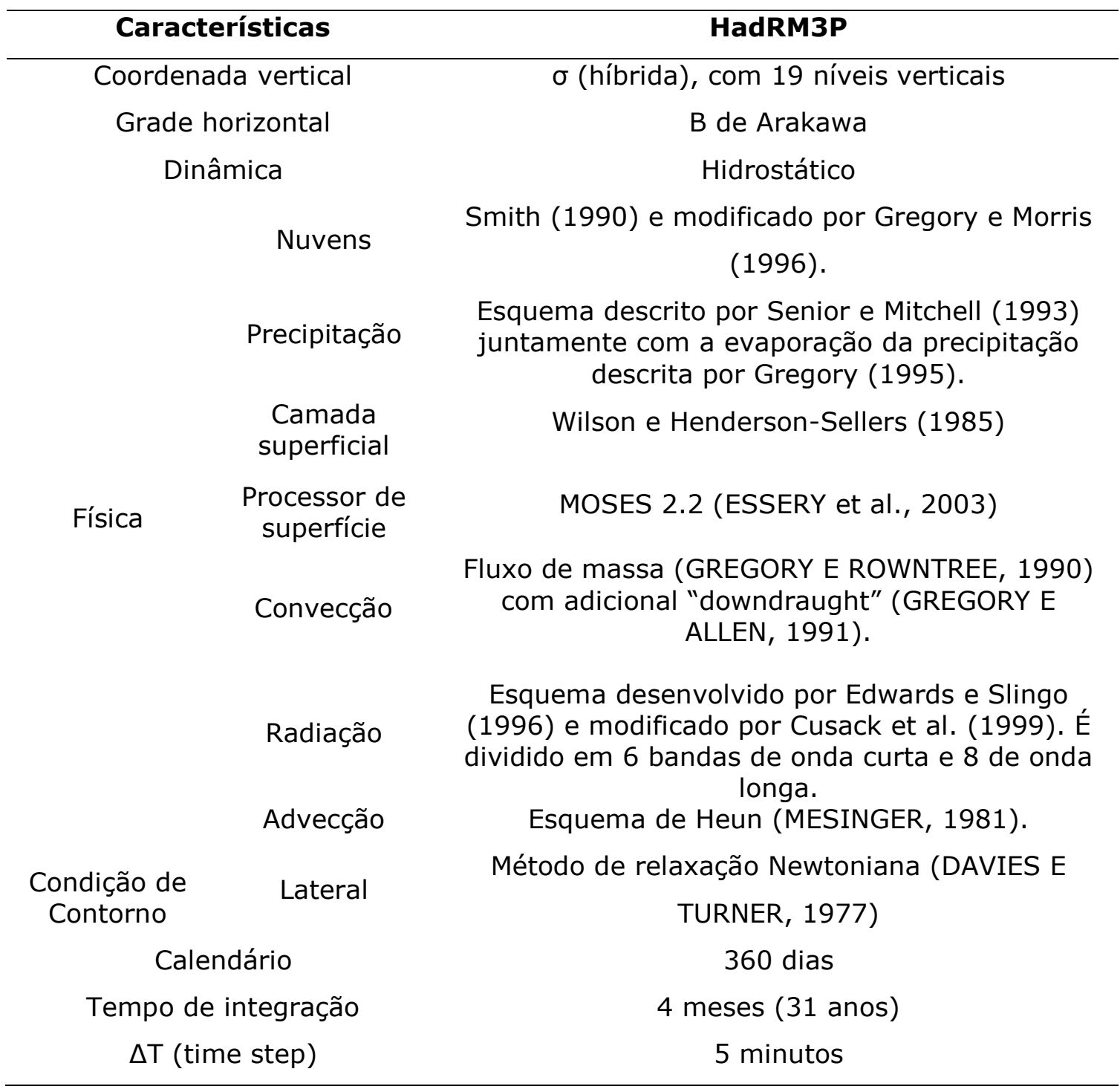

As integrações com o PRECIS foram forçadas com as condições de contorno provenientes do modelo global HadGEM2-ES (Hadley Centre Global Environmental Model Version 2 - Earth System). Este modelo é o estado-daarte do sistema terrestre, composto por um modelo de circulação global da atmosfera acoplado a um modelo oceânico, e que também inclui vegetação dinâmica, biologia do oceano e química da atmosfera (CAESAR et al., 2013). A resolução horizontal da componente atmosférica é de aproximadamente $1,25^{\circ} \mathrm{X}$ $1,875^{\circ}$ de latitude/longitude (N96) com 38 níveis verticais, e a componente oceânica de $1^{\circ}$ (aumentando para $1 / 3$ de grau no equador) com 40 níveis verticais (COLLINS et al., 2011).

O período de integração com o PRECIS compreende o período de dezembro de 1979 a novembro de 2005. Porém, o primeiro ano de integração (spin-up) foi descartado para permitir que a atmosfera e a superfície terrestre 
sejam ajustadas a um estado de equilíbrio mútuo (WILSON et al. 2015). Sendo assim, o período utilizado para análise compreende de 1981 a 2005.

A área selecionada para integração do modelo (Figura 1) está compreendida entre $17,5^{\circ} \mathrm{S}$ a $7,25^{\circ} \mathrm{N}$ de latitude ( $\mathrm{nx}: 147$ pontos) e $62,25^{\circ} \mathrm{W}$ a $32^{\circ} \mathrm{W}$ de longitude (ny: 124 pontos).

A partir do processamento dos dados de saída do modelo, a análise das simulações foi realizada considerando apenas as variáveis de interesse neste trabalho, são elas: temperatura a 1,5 metros (calculado a partir da interpolação da temperatura a superfície e o primeiro nível do modelo) e Precipitação.

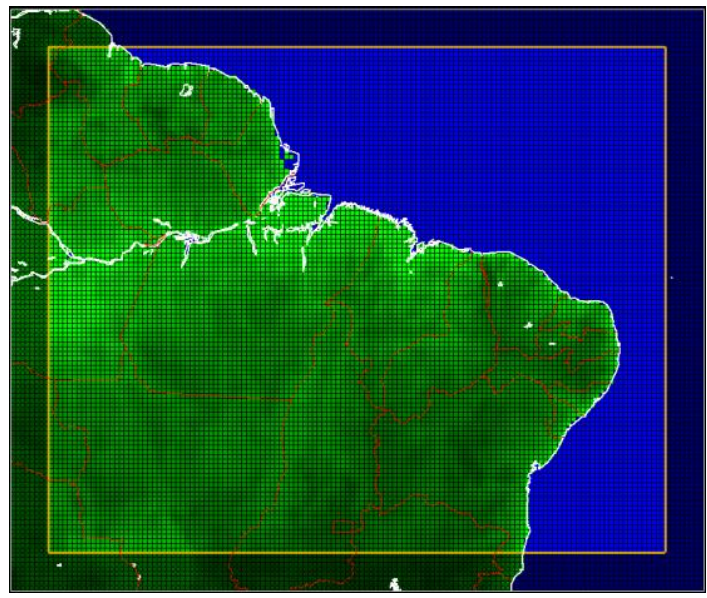

Figura 1 - Domínio das integrações com o PRECIS. Abrangendo o norte-nordeste da América do Sul e oceano Atlântico adjacente.

\subsection{AVALIAÇÃO DO DESEMPENHO DO MODELO REGIONAL}

A destreza dos Modelos Regionais em simular condições climáticas em um determinado local pode ser avaliada usando uma variedade de técnicas (FLATO et al., 2013). Neste trabalho, empregou-se medidas estatísticas, as quais são comumente utilizadas neste tipo de análise e recomendadas pela Organização Meteorológica Mundial (OMM), como descrito em Gordon e Shaykewich (2000):

a) Viés

Representa uma medida simples de confiabilidade do modelo em reproduzir as observações, onde os valores mais próximos de zero correspondem a menores erros da simulação comparado ao observado. Além disso, valores positivos indicam superestimativa e valores negativos subestimativa. É obtido pela diferença entre as séries de dados simulados e dados observados.

$$
\text { viés }=M-O
$$

Onde $M$ representa o dado simulado pelo PRECIS (precipitação e temperatura), e O dado observado pelo CPC (precipitação) e CRU (temperatura). 


\section{b) Raiz do Erro Médio Quadrático (REMQ)}

Medida de erro muito utilizada na comparação entre valores simulados e observados. Este parâmetro é muito sensível a grandes desvios entre os valores das séries comparadas, o que o torna mais relevante quando se trata de avaliação de grandes erros (LIMA E ALVES, 2009). Sempre será um valor positivo e quanto mais próximo de zero, maior a semelhança entre as séries.

$$
R E Q M=\sqrt{\frac{\sum_{i=1}^{N}\left(M_{i}-O_{i}\right)^{2}}{N}}
$$

Sendo $N$ o número de elementos da amostra, $M$ representa o dado simulado pelo PRECIS (precipitação e temperatura), e $O$ dado observado pelo CPC (precipitação) e CRU (temperatura). A unidade deste parâmetro é a mesma da variável analisada.

\section{c) Correlação temporal (Cor)}

Foi calculada a correlação em cada ponto de grade para todos os tempos das séries de dados simulado e observado. A correlação pode assumir valores entre -1 e 1 , onde este último indica uma perfeita correlação e quando nulo indica que não há correlação entre as séries de dados.

$$
\text { Cor }=\frac{\sum_{i=1}^{N}\left(O_{i}-\bar{O}\right)\left(M_{i}-\bar{M}\right)}{\sqrt{\left[\sum_{i=1}^{N}\left(M_{i}-\bar{M}\right)^{2} \sum_{i=1}^{N}\left(O_{i}-\bar{O}\right)^{2}\right]}}
$$

Onde $\mathrm{N}$ é o número de elementos da amostra, $\mathrm{M}$ o dado simulado pelo PRECIS (precipitação e temperatura), e O dado observado pelo CPC (precipitação) e CRU (temperatura). Esta medida é adimensional.

A área em estudo refere a Amazônia oriental, abrangendo os estados do Pará, Amapá e Maranhão, Tocantins, Mato Grosso, Amazonas, Piauí (Figura 2, domínio maior), a qual está inserida no domínio de integração do modelo (Figura 1). Para uma análise qualitativa, os dados do modelo regional (HadRM3P) foram interpolados para a mesma resolução horizontal dos dados observados do CPC e do $\operatorname{CRU}\left(0,5^{\circ} \times 0,5^{\circ}\right.$ de lat/lon), aplicando uma função do software GrADS, a qual usa o método de interpolação bilinear. Posteriormente, foram realizados os cálculos destas medidas estatísticas em cada ponto de grade, para ambas as séries de dados. Os resultados desta análise são apresentados em mapas.

Também foi examinada a habilidade do modelo regional em reproduzir o ciclo anual da precipitação e da temperatura. Para tanto, selecionou-se três regiões no domínio da Amazônia oriental, a partir daqui denominadas de R1, R2 e R3 (Figura 2), as quais são baseadas no estudo de Santos et al. (2015) que dividiu a Amazônia em sub-regiões com precipitação homogênea aplicando a análise de cluster hierárquico. Para esta etapa, determinou-se, para cada subregião, a partir dos dados simulados e observados, o viés (equação 1 ), o desvio 
Padrão de uma amostra a partir daqui simbolizado por STDEV (equação 4) e a média aritmética (equação 5).

$$
S T D E V=\sqrt{\frac{\sum_{i=1}^{n}\left(x_{i}-\bar{x}\right)^{2}}{n-1}}
$$

Onde $\mathrm{n}$ é o número de elementos da amostra, $\mathrm{x}$ _i o dado da série (simulado ou observado) e $\mathrm{x}^{-}$é a média da amostra dada pela equação abaixo:

$$
\bar{x}=\frac{\left(x_{1}+x_{2}+x_{3}+\cdots+x_{n}\right)}{n}
$$

Onde $\mathrm{x}_{1}, \mathrm{x}_{2}, \mathrm{x}_{3} \ldots \mathrm{x}_{\mathrm{n}}$ são os elementos da amostra (dados do modelo ou observado) e n é o número de elementos da amostra

Os dados do modelo global se referem ao período de 1984 a 2005, enquanto os do modelo regional e das observações, de 1981 a 2005. Sendo assim, as análises comparativas entre os modelos e observação foram feitas no período de 1984 a 2005, e as referentes somente ao modelo regional e observação, feitas no intervalo de 1981 a 2005.

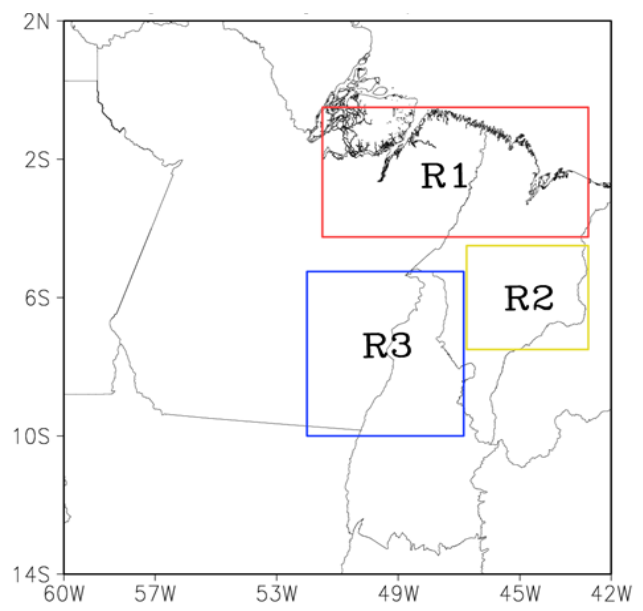

Figura 2 - Regiões de estudo: R1 (Lat: $4,25^{\circ} \mathrm{S}$ a $0,5^{\circ} \mathrm{S} / \mathrm{Lon}: 51,50^{\circ} \mathrm{W}$ a $42,75^{\circ} \mathrm{W}$; em vermelho), R2 (Lat: $7,5^{\circ} \mathrm{S}$ a $4,5^{\circ} \mathrm{S} /$ Lon: $46,75^{\circ} \mathrm{W}$ a $42,75^{\circ} \mathrm{W}$; em amarelo) e R3 (Lat: $10,0^{\circ} \mathrm{S}$ a $5,25^{\circ} \mathrm{S} /$ Lon: $52,0^{\circ} \mathrm{W}$ a $46,85^{\circ} \mathrm{W}$; em azul). O domínio maior representa a Amazônia Oriental (Lat: $14,0^{\circ} \mathrm{S}$ a $2,0^{\circ} \mathrm{S} /$ Lon: $60,0^{\circ} \mathrm{W}$ a $42,0^{\circ} \mathrm{W}$ ).

\section{RESULTADOS E DISCUSSÃO}

A destreza do HadRM3P em simular o clima atual referente a precipitação e a temperatura do ar, sobre a Amazônia oriental, foi baseada na comparação com observações provenientes do CPC e CRU, respectivamente. Os resultados são apresentados em mapas sazonais do Viés, Raiz do Erro Médio Quadrático (REMQ) e Correlação temporal (Cor). Buscou-se, também, avaliar o ganho em se utilizar um modelo regional aninhado a um modelo global como forma mais 
realística em representar o clima da região. Além disso, são apresentadas estatísticas que indicam o grau de proximidade entre as séries de dados.

\subsection{PRECIPITAÇÃO}

\subsubsection{MÉDIA SAZONAL}

A figura 3 apresenta os mapas da precipitação sazonal simulada, HadRM3P e HadGEM2-ES, e observada (CPC), referente ao clima atual (média de 21 anos, 1985 - 2005). Para esta comparação, optou-se por manter a resolução original dos dados, a fim de analisar o ganho em se utilizar a técnica de downscaling dinâmico para prever o clima regional sobre o uso somente do modelo global para tal fim.

As observações pelo CPC mostram que no verão austral (DJF, DezembroJaneiro-Fevereiro) os maiores volumes de chuva ocorrem no sudoeste da área de estudo, associada à Zona de Convergência do Atlântico Sul (ZCAS), a qual é caracterizada pela presença de uma extensa banda de nebulosidade orientada no sentido noroeste-sudeste (KOUSKY, 1988), que explica os máximos de chuva sobre a Amazônia durante este trimestre (CARVALHO et al., 2004). Neste contexto, quanto às simulações, o modelo global estende esta área de máxima precipitação associada à ZCAS, enquanto o modelo regional desloca esta área de máxima para sul e apresenta menor magnitude desta variável, quando comparado ao observado. Ainda neste período sazonal, de acordo com o CPC, observa-se outro máximo de precipitação $(8-12 \mathrm{~mm} / \mathrm{dia})$ localizado na faixa litorânea dos estados do Amapá e Pará, abrangendo, também, a ilha do Marajó, associado ao posicionamento mais central da banda de nebulosidade da Zona de Convergência Intertropical, que se encontra em latitudes equatoriais (DE SOUZA et al., 2004). No tocante aos modelos, apesar de subestimar a precipitação nesta região de influência da ZCIT, o modelo regional apresenta melhor acurácia que o modelo global.

No trimestre de MAM (Março-Abril-Maio), as observações mostram uma redução da precipitação na porção sul-sudeste da Amazônia oriental, devido à redução de números de episódios de ZCAS e/ou de sistemas frontais (DE SOUZA et al., 2009), e aumento da atividade convectiva no norte da região associada a atuação da ZCIT, principal sistema meteorológico indutor da precipitação sobre a região durante os meses de outono do Hemisfério Sul, onde também ocorre o ápice da estação chuvosa (DE SOUZA et al., 2004; DE SOUZA E ROCHA, 2006). Assim, esses máximos de precipitação podem ser explicados pela proximidade da Zona de Convergência Intertropical (ZCIT) combinado aos mecanismos de circulação de brisa que formam as condições dinâmicas de grande e meso escalas, responsáveis pela formação das Linhas de Instabilidade (LI) ao longo do norte e nordeste da Amazônia (COHEN et al., 1995). Quanto às simulações, nota-se que os modelos apresentam deficiência em capturar as áreas de maior precipitação na porção norte da região, principalmente o HadRM3P. Contudo, o modelo regional mostra um ganho em relação ao modelo global em simular a precipitação no extremo noroeste do Pará, litoral leste do Amapá, e especialmente na porção sudeste da área de estudo, onde o modelo detém informações das características regionais.

Em comparação aos trimestres anteriores, JJA (Junho-Julho-Agosto) é caracterizado por uma redução significativa na precipitação em quase toda a Amazônia oriental, configurando a estação de seca na região. Observa-se, 
extensa área de menor precipitação (1-4 $\mathrm{mm} / \mathrm{dia})$ inclinada no sentido sudoeste-nordeste e restrita na faixa latitudinal entre $9^{\circ} \mathrm{S}$ e $2^{\circ} \mathrm{S}$. O modelo regional apresenta um ganho sobre o modelo global ao capturar bem a variabilidade espacial da precipitação nesta faixa latitudinal, onde são observados os menores volumes pluviométricos. Ademais mostra uma leve melhoria na representação da precipitação associada a ocorrência de Linhas de Instabilidade (LIs) no litoral da região, as quais estão associadas às características inerentes ao modelo regional em conseguir capturar os denominados sistemas chamados sub-grade, que são incapazes de serem detectadas pelos modelos globais em virtude da baixa resolução espacial.

Na estação de transição entre o inverno e o verão austrais, o trimestre de SON (Setembro-Outubro-Novembro), pode ser verificado o desenvolvimento da atividade convectiva na Amazônica, associada ao início do sistema de monção da América do Sul (ZHOU E LAU, 1998; Vera et al., 2006), onde são observadas (CPC) precipitações entre 4 e $8 \mathrm{~mm} /$ dia no sudeste da região e o deslocamento da área de menor precipitação (1 a $4 \mathrm{~mm} /$ dia) no sentido sudeste-noroeste. Quanto à estas características observadas, o modelo regional apresentou melhor acurácia em simular núcleo de maior precipitação situado na fronteira sul do estado do Pará. Além disso, também apresentou melhoria da captura da variabilidade espacial da faixa de precipitação de menor intensidade neste período sazonal. 

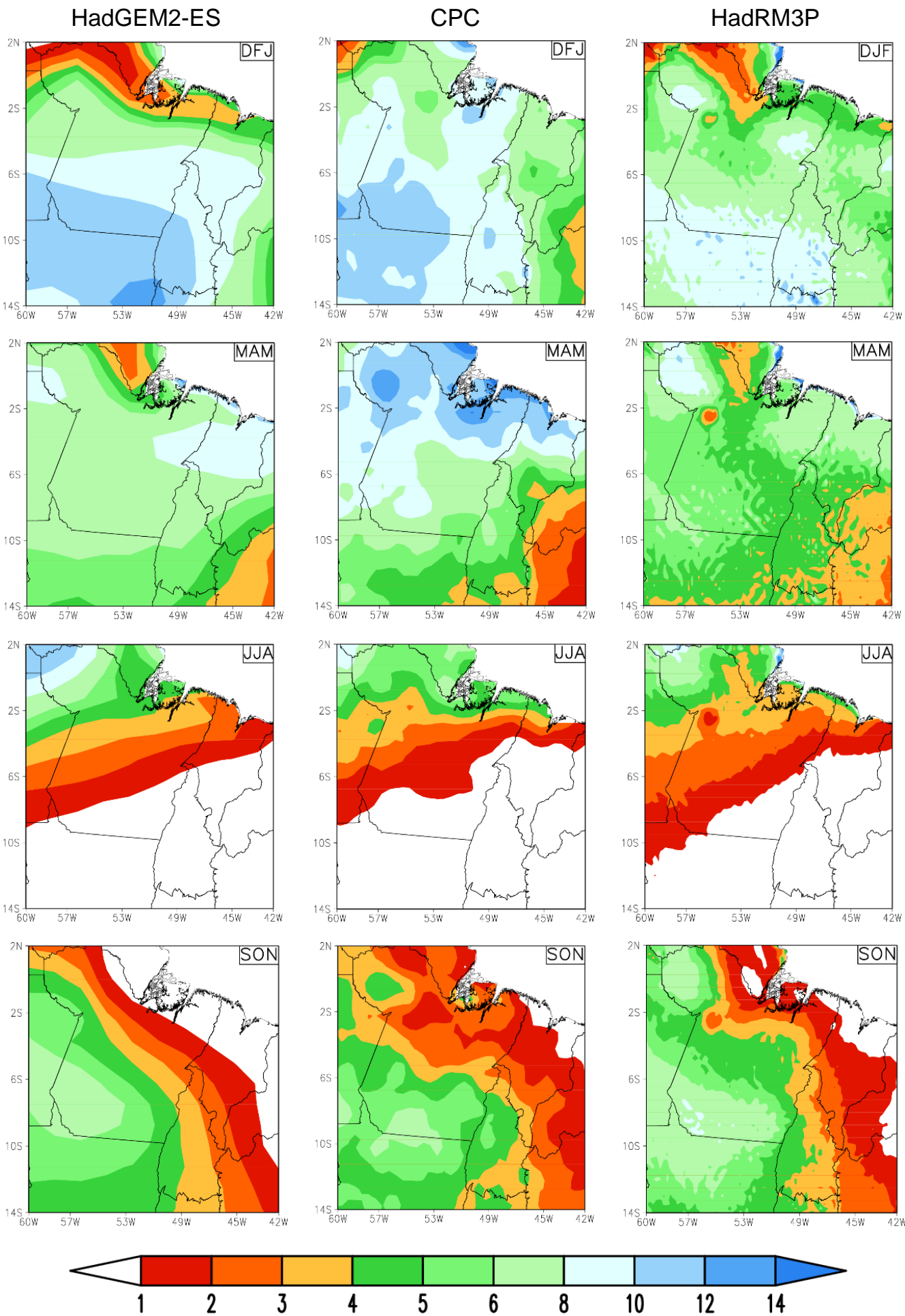

Figura 3 - Média (1984 - 2005) da precipitação observada CPC e simulada pelos modelos global HadGEM2-ES e regional HadRM3P. As cores indicam a intensidade da precipitação $\left(\mathrm{mm}^{\mathrm{dia}}{ }^{-1}\right)$. Os conjuntos de dados encontram-se em sua resolução horizontal original (lat/lon): $0,5^{\circ}$ (CPC), $1,25^{\circ} \times 1,875^{\circ}$ (HadGEM2-ES) e $0,22^{\circ}$ (HadRM3P). Médias de dezembro a fevereiro (DJF), março a maio (MAM), junho a agosto (JJA) e de setembro a outubro (SON). 


\subsubsection{AVALIAÇÃo do MOdelo CLIMÁtico REgIONAL QUANTO À PRECIPITAÇÃOO}

Nesta seção são mostrados os mapas do viés (simulado menos observado), Raiz do Erro Médio Quadrático (REMQ) e da correlação entre as séries de dados simulado e observado no período de 1981 a 2005.

A figura 4 mostra a distribuição espacial do viés da precipitação sazonal. Utilizou-se valores absolutos entre \pm 2 como limiar indicativo de boa concordância do modelo com relação a observação, onde valores positivos e negativos, maiores que este limiar, indicam superestimativa e subestimativa do modelo, respectivamente (DE SOUZA et al., 2016). Nesta figura, verifica-se que o modelo regional subestima a precipitação sobre a maior parte da Amazônia oriental nos trimestres chuvosos (DJF e MAM), especialmente nos estados do Pará e Amapá, onde é simulado de 4 a $8 \mathrm{~mm} /$ dia a menos de chuva comparado ao observado. De acordo com Alves e Marengo (2010), apesar do modelo simular corretamente o posicionamento da ZCIT, a precipitação associada a este sistema não consegue adentrar ao continente, resultando em elevados desvios negativos de precipitação no extremo norte da América do Sul durante o trimestre de DJF. E válido ainda destacar a subestimativa da precipitação na região da ZCAS, localizada na parte sudoeste da área de estudo. A redução de chuva sobre a Amazônia pelos modelos climáticos está relacionada ao uso de inadequada parametrização de convecção (SOUZA, 2006; OYAMA, 2006; ALVES E MARENGO, 2010) e de camada limite planetária (VALVERDE E MARENGO, 2010). Além disso, Chou et al. (2014), utilizando o modelo regional Eta aninhado ao modelo global HadGEM2-ES, também encontraram subestimativa da precipitação nesta região no verão austral. Destaca-se, ainda, o persistente viés úmido (superestimativa) ao longo do ano no extremo leste do Estado do Amapá, especialmente no verão (DJF) e inverno (JJA) austrais com até 10 $\mathrm{mm} /$ dia a mais do observado. $\mathrm{Na}$ primavera austral (SON), o modelo superestima levemente a precipitação de 2 a $4 \mathrm{~mm} /$ dia em regiões localizadas no centro, no sudoeste e no noroeste do estado do Pará.

A Figura 5 apresenta a espacialização do REMQ (Raiz do Erro Médio Quadrático), que mede a acurácia do modelo, onde quanto mais próximo de zero for este parâmetro, menor o erro e maior a eficiência do modelo em reproduzir os dados observados. Partindo-se desta definição, é possível notar na Figura 5 que os maiores valores de REQM ocorrem nos trimestres mais chuvosos (DJF e MAM) da região, especialmente sobre a porção norte, que abrange os estados do Maranhão, Pará e Amapá. Dentre estes, destaca-se o norte do estado do Amapá, onde o erro na simulação da precipitação pode chegar a 10 $\mathrm{mm} / \mathrm{dia}$, em MAM, que podem estar relacionados à dificuldade do modelo regional em captar adequadamente a atuação da ZCIT na região. Os menores valores de REQM são encontrados nos trimestres de JJA e SON, onde a atividade convectiva é reduzida na região. Sobre isto, destaca-se a alta a concordância da simulação com a observação no inverno austral (JJA), exceto no extremo leste do estado do Amapá, onde são encontrados erros de até $8 \mathrm{~mm} / \mathrm{dia}$. 

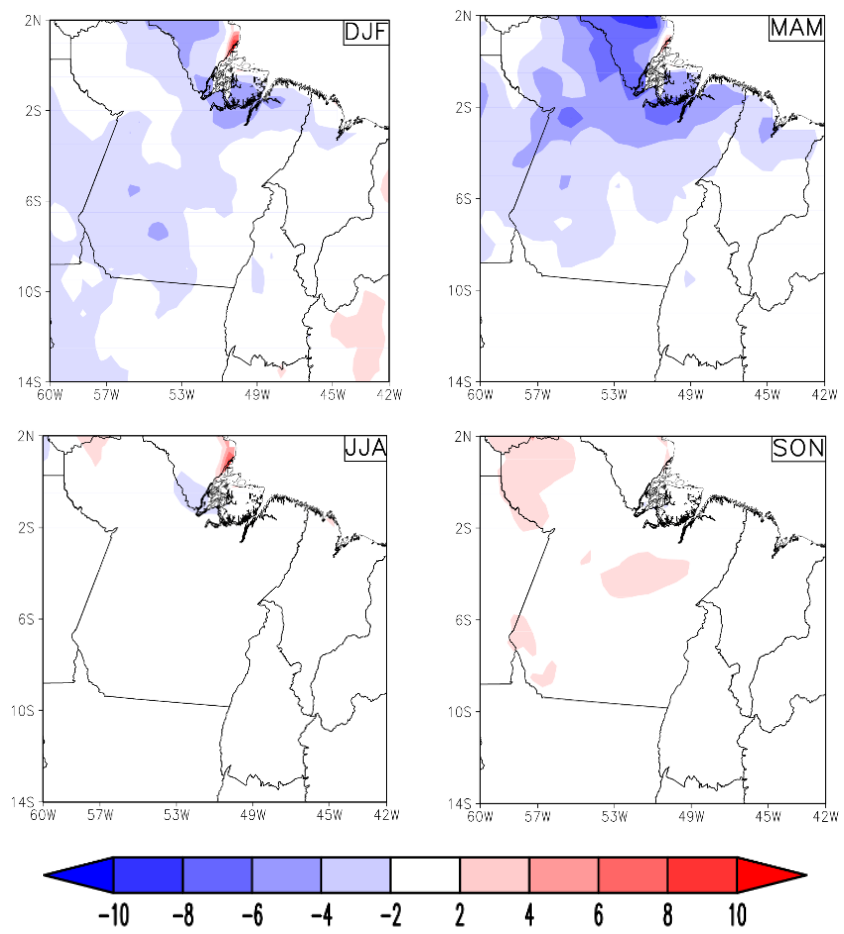

Figura 4 - Viés absoluto da precipitação sazonal observada pelo CPC e a simulada pelo HadRM3P sobre a Amazônia Oriental. A escala de cores refere-se a diferença entre o simulado e o observado no período de 1981 a 2005, onde as cores em vermelho indicam valores positivos para viés (superestimativa) e as cores em azul, viés negativo (subestimativa). Ambos, CPC e HadRM3P, na resolução horizontal de 0,50 de lat/lon. Unidade: $\mathrm{mm} \cdot \mathrm{dia}^{-1}$.
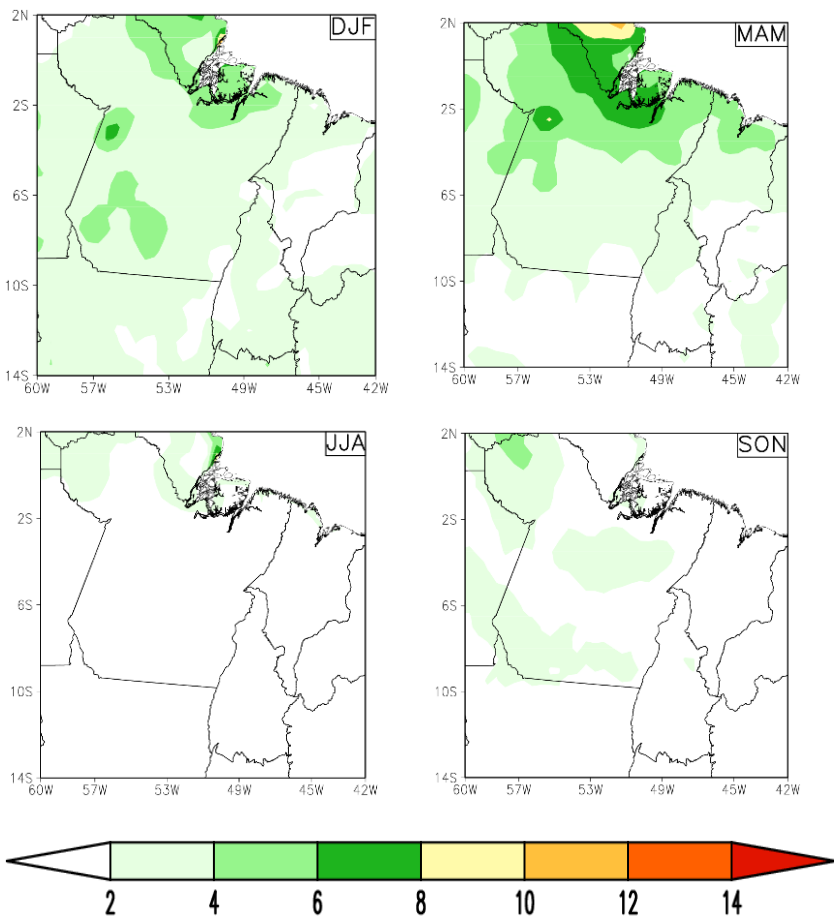

Figura 5 - Espacialização da Raiz do erro quadrático médio (REQM) entre a precipitação simulada (HadRM3P) e observada (CPC) na Amazônia Oriental no período de 1981 a 
2005. A legenda em cores refere-se à acurácia do modelo. Ambos, CPC e HadRM3P, na resolução horizontal de $0,5^{\circ}$ de lat/lon. Unidade: $\mathrm{mm}$.dia ${ }^{-1}$.

Os mapas do coeficiente de correlação temporal da precipitação sazonal simulada (HadRM3P) e observada (CPC) no período de 1981 a 2005 são mostrados na Figura 6, onde nota-se que em geral, apesar dos erros sistemáticos quanto a distribuição espacial da precipitação na Amazônia oriental, o modelo regional apresenta um bom desempenho em capturar a variabilidade temporal desta variável. Neste contexto, destacam-se os trimestres de JJA e SON, coeficientes de até 0,8 no litoral da região e na porção sul, assim como no trimestre de MAM onde é mostrado coeficiente de mais de 0,8 em pequenas regiões na porção sul da área de estudo. No tocante a este último trimestre, também é válido comentar que apesar do modelo apresentar um bom desempenho em simular a série temporal da precipitação, seu desempenho cai à medida que segue para a porção norte da região, onde, neste período sazonal, são observados altos índices pluviométricos. Isto revela, que o modelo não tem acurácia em simular tanto a variabilidade espacial quanto a variabilidade temporal da precipitação associada a ZCIT. No verão austral (DJF), destaca-se a correlação temporal positiva entre as séries simulada e observada entre 0,4 e 0,6 sobre o litoral dos estados do Pará e Maranhão.

O ciclo anual da precipitação média de 1984 a 2005 sobre as sub-regiões (R1, R2 e R3) na Amazônia oriental pode ser visto na figura 7. Desta forma, é possível avaliar o desempenho do modelo climático regional (HadRM3P) com respeito ao clima médio da precipitação. Além disso, foi incluída a simulação pelo HadGEM2-ES, possibilitando, assim, qualificar o ganho do modelo regional em relação ao global em simular o clima atual. Para tanto, as resoluções dos dados, simulados e observado, foram mantidas em sua forma original. Em geral, os modelos são capazes de reproduzir o ciclo anual da precipitação nas regiões homogêneas, sendo melhor representada na estação seca. Na região 1 - R1 (Fig. 7a), o ciclo anual da precipitação apresenta duas estações bem definidas: uma chuvosa, que vai de janeiro a maio, com pico máximo de pouco mais de 13 $\mathrm{mm} /$ dia em março, e uma estação seca, que vai de julho a novembro. No entanto, os modelos climáticos não apresentaram bom desempenho em simular a precipitação na região, pois subestimaram e identificaram erroneamente o ápice da estação chuvosa, dois meses após o observado pelo CPC. Apesar disso, o modelo regional teve melhor acurácia que o modelo global na reprodução da estação seca. A sub-região R1 abrange regiões litorâneas do Pará e Maranhão, e como detectado no tópico anterior, o modelo tem dificuldades em simular a precipitação nos trimestres de DJF e MAM sobre as regiões próximas ao litoral (Figura 3). Em R2 (Fig 7b), os modelos se aproximam mais do observado pelo CPC, reproduzindo melhor a estação seca da região, que vai de junho a setembro. Na estação chuvosa, que de acordo com o CPC vai de janeiro a abril, com máximo de $8 \mathrm{~mm} /$ dia em março, o modelo regional apresentou melhor desempenho que o modelo global, porém subestima em quase $1 \mathrm{~mm} / \mathrm{dia}$ a precipitação e adianta o pico da estação chuvosa para o mês de fevereiro. Em relação a R3 (Figura 7c), em termos de magnitude da precipitação na estação chuvosa, o HadGEM2-ES aproximou-se mais do observado que o HadRM3P. Além disso, ainda neste período, nota-se, que o modelo regional apresenta o mesmo comportamento do modelo global, apontando máximo de precipitação no mês de fevereiro, o que indica que o modelo regional recebeu as mesmas características do modelo global. 

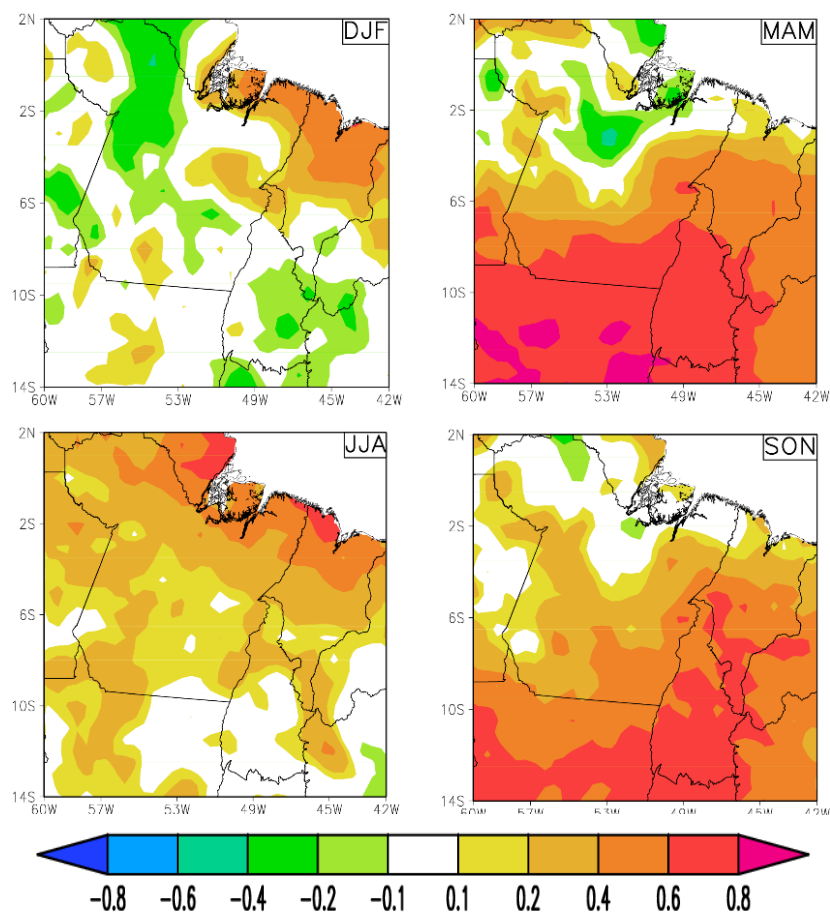

Figura 6 - Correlação temporal entre as séries da precipitação simulada (HadRM3P) e observada (CPC) para o período de 1981 a 2005. A escala de cores refere-se ao coeficiente de correlação entre as séries. Ambos, CPC e HadRM3P, na resolução horizontal de $0,5^{\circ}$ de lat/lon. Unidade: Adimensional.
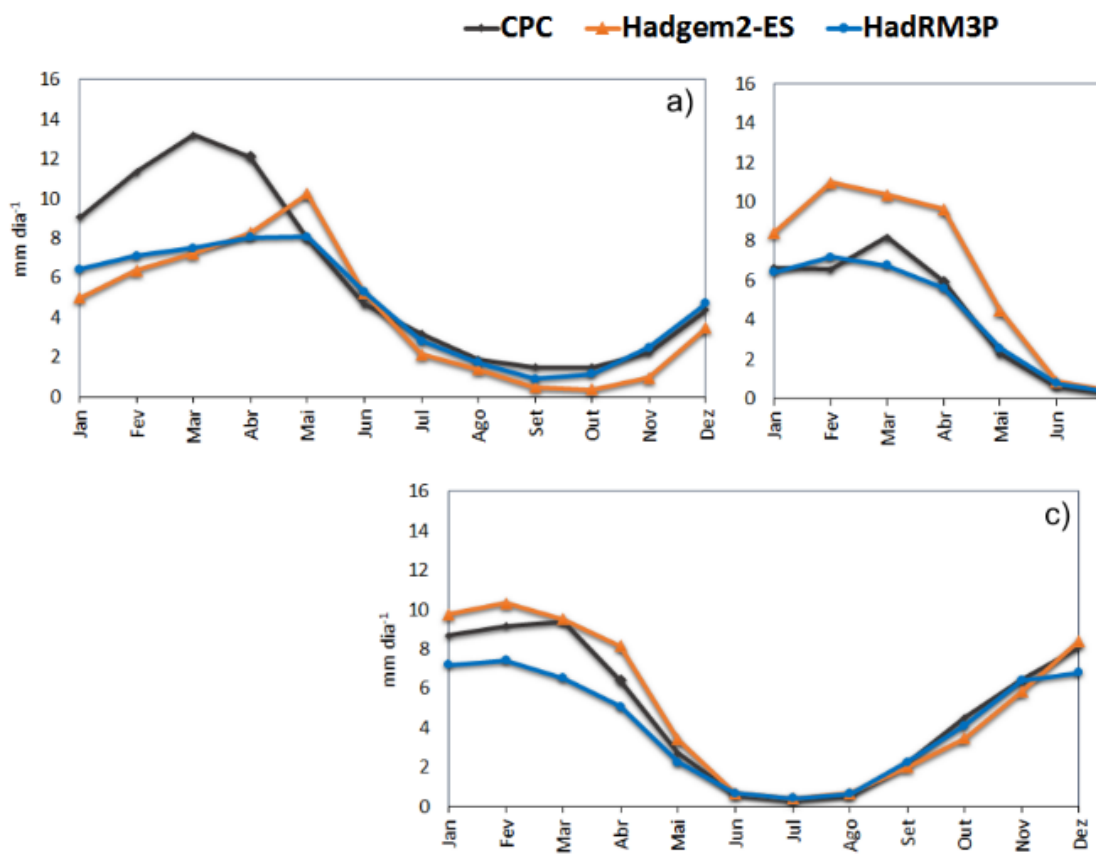

Figura 7 - Figura 7 - Ciclo anual médio (1984 - 2005) da precipitação (mm.dia $\left.{ }^{-1}\right)$ observada pelo CPC e simulada pelos modelos global (HadGEM2-ES) e regional (HadRM3P) nas sub-regiões de estudo (a) R1, (b) R2 e (c) R3. A linha preta representa a 
observação, a laranja o modelo global e a linha azul, o modelo regional. Cada um em sua resolução horizontal (lat/lon) original: $0,5^{\circ} \times 0,5^{\circ}$ (CPC), $1,25^{\circ} \times 1,875^{\circ}$ (HadGEM2-ES) e $0,22^{\circ} \times 0,22^{\circ}$ (HadRM3P).

Na Tabela 2 são mostrados os escores estatísticos entre a precipitação simulada e observada nas sub-regiões R1, R2 e R3. Para R1, nota-se que, ao longo do ano, a magnitude do viés é maior no trimestre MAM, mostrando subestimativa da precipitação por parte do modelo, e diferença de $1,1 \mathrm{~mm} / \mathrm{dia}$ entre o desvio padrão do modelo e o observado. Por outro lado, em SON, o viés é o menor em magnitude em relação aos demais trimestres, onde o HadRM3P subestima levemente a precipitação $(0,2 \mathrm{~mm} / \mathrm{dia})$ e a diferença entre os desvios padrões do modelo e da observação de apenas 0,3 mm/dia. No trimestre de JJA, o modelo mostra-se capaz de reproduzir a variabilidade da precipitação nesta sub-região ao apresentar desvio padrão igual ao observado pelo CPC, apesar disto, superestima levemente a precipitação em $0,3 \mathrm{~mm} /$ dia. Comparando com as demais sub-regiões, em R2, o modelo simula melhor a precipitação ao longo do ano, com vieses de magnitude de apenas 0,2 e 0,3 mm/dia. Apresentando melhor desempenho nas simulações do trimestre de JJA, viés de 0,2 mm/dia e diferenciando-se em apenas $0,1 \mathrm{~mm} /$ dia para mais, em relação ao desvio padrão observado. Apesar de subestimar a precipitação em apenas 0,3 mm/dia, no trimestre de MAM, o modelo não é capaz de reproduzir a grande variabilidade observada desta variável, que apresenta desvio de 1,8 mm/dia. Para R3, o melhor desempenho do modelo ocorre nos trimestres de JJA e SON, onde a precipitação observada é superestimada em apenas $0,1 \mathrm{~mm} /$ dia e subestimada em 0,2 mm/dia. Deste modo, o modelo apresenta seu melhor desempenho no trimestre de JJA, com desvio padrão de $0,4 \mathrm{~mm} /$ dia, enquanto que o observado é de $0,3 \mathrm{~mm} / \mathrm{dia}$.

Tabela 2 - Escores estatísticos entre a precipitação $\left(\mathrm{mm}^{\mathrm{d}} \mathrm{dia}^{-1}\right)$ sazonal observada (CPC) e a simulada (HadRM3P) para o período de 1981 a 2005 nas sub-regiões de estudo R1, R2 e R3. Viés refere-se a diferença entre a média da simulação e a média da observação, STDEV é o desvio padrão da série. Os resultados são apresentados em médias trimestrais: Dezembro, Janeiro e Fevereiro (DJF), Março, Abril e Maio (MAM), Junho, Julho e Agosto (JJA) e Setembro, Outubro e Novembro (SON). Ambos, CPC e HadRM3P, na resolução horizontal de $0,5^{\circ}$ de lat/lon.

\begin{tabular}{|c|c|c|c|c|c|c|c|c|c|}
\hline \multirow[b]{2}{*}{ DJF } & \multicolumn{3}{|c|}{$R 1$} & \multicolumn{3}{|c|}{$R 2$} & \multicolumn{3}{|c|}{ R3 } \\
\hline & Viés & STDEV & Media & Viés & STDEV & Media & Viés & STDEV & Media \\
\hline $\begin{array}{c}\text { Simulado } \\
\text { (HadRM3P) }\end{array}$ & & 1,3 & 6,1 & & 0,9 & 6,2 & & 0,8 & 7,2 \\
\hline $\begin{array}{l}\text { Observado } \\
\text { (CPC) }\end{array}$ & $-1,9$ & 1,5 & 8,1 & 0,3 & 1,4 & 5,9 & $-1,4$ & 1,3 & 8,6 \\
\hline \multicolumn{10}{|l|}{ MAM } \\
\hline $\begin{array}{c}\text { Simulado } \\
\text { (HadRM3P) }\end{array}$ & & 1,1 & 7,9 & & 0,8 & 5,1 & & 0,6 & 4,7 \\
\hline $\begin{array}{l}\text { Observado } \\
\text { (CPC) }\end{array}$ & $-3,0$ & 2,2 & 10,9 & $-0,3$ & 1,8 & 5,4 & $-1,4$ & 1,3 & 6,0 \\
\hline \multicolumn{10}{|l|}{ AנJA } \\
\hline $\begin{array}{l}\text { Simulado } \\
\text { (HadRM3P) }\end{array}$ & 0,3 & 0,8 & 3,5 & 0,2 & 0,4 & 0,5 & 0,1 & 0,4 & 0,6 \\
\hline
\end{tabular}




\begin{tabular}{|c|c|c|c|c|c|c|c|c|c|}
\hline $\begin{array}{l}\text { Observado } \\
\text { (CPC) }\end{array}$ & & 0,8 & 3,2 & & 0,3 & 0,4 & & 0,3 & 0,5 \\
\hline \multicolumn{10}{|l|}{ SON } \\
\hline $\begin{array}{l}\text { Simulado } \\
\text { (HadRM3P) }\end{array}$ & & 0,8 & 1,7 & & 0,8 & 1,8 & & 0,8 & 4,4 \\
\hline $\begin{array}{l}\text { Observado } \\
\text { (CPC) }\end{array}$ & $-0,2$ & 1,1 & 1,8 & $-0,2$ & 1,0 & 2,0 & $-0,2$ & 1,1 & 4,6 \\
\hline
\end{tabular}

\subsection{TEMPERATURA}

\subsubsection{MÉDIA SAZONAL}

A Figura 8 apresenta a distribuição espacial sazonal da temperatura do ar na Amazônia oriental, referente às observações (CRU) e às simulações (HadGEM2-ES e HadRM3P) para o período de 1984 a 2005. De acordo com Nobre et al. (2010), devido aos altos valores de radiação solar incidente no topo da atmosfera, a temperatura média do ar, em escala de tempo sazonais, não apresenta altas amplitudes em grande parte da Amazônia, exceto no seu lado meridional (Rondônia e Mato Grosso). Nota-se, na Figura 8, que no verão e outono austrais (DJF e MAM), trimestres onde ocorrem os maiores volumes de chuva na Amazônia oriental (CPC, Fig. 03), a variabilidade espacial da temperatura, mostrada pelo CRU, apresenta configuração semelhante entre estes trimestres, variando em média entre $24^{\circ}$ e $28^{\circ} \mathrm{C}$. Os modelos climáticos foram capazes de representar esta característica de semelhança espacial da temperatura entre DJF e MAM, porém com maior variabilidade, oscilando valores médios de $22^{\circ}$ a $28^{\circ} \mathrm{C}$. De acordo com o CRU, observa-se, no inverno austral, uma estreita faixa de resfriamento no sudeste e sudoeste da Amazônia oriental, a partir de $20^{\circ} \mathrm{C}$, que pode ser associado a eventos que produzem geadas no sul e sudeste do Brasil, e que causam quedas significativas na temperatura sobre a Amazônia (MARENGO E NOBRE, 2009). Em geral, para este período sazonal, nota-se um ganho sobre o modelo global em simular a intensidade da temperatura, visto que o modelo regional simula as áreas de intensa temperatura, entre $24^{\circ}$ e $28^{\circ} \mathrm{C}$, sobre grande parte da Amazônia oriental. Além disso, reduz a extensão da área de resfriamento, ficando mais próximo ao observado pelo CRU. O trimestre de SON, é caracterizado pelas temperaturas mais elevadas do ano, entre 26 e $28^{\circ} \mathrm{C}$ em grande parte da Amazônia oriental, podendo atingir, em média, $30^{\circ} \mathrm{C}$ no nordeste da região, norte da ilha do Marajó-PA e na fronteira noroeste entre os estados do Pará e Amazonas. Resumidamente, o modelo regional apresentou melhor desempenho sobre o modelo global ao simular a extensão da área de temperaturas mais extremas (entre $28^{\circ}$ e $30^{\circ} \mathrm{C}$ ), associada a melhor representação das características da superfície no modelo regional. 

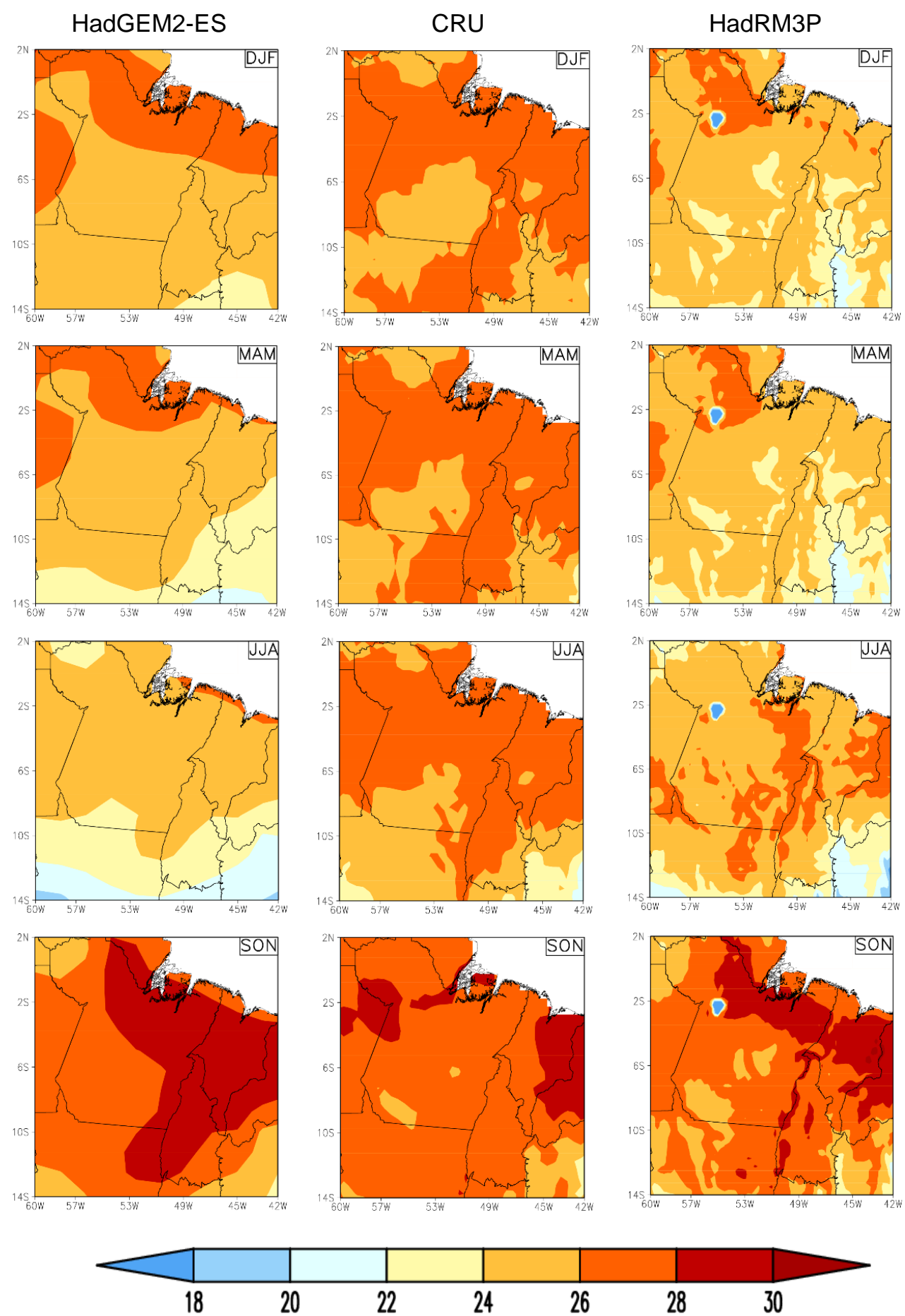

Figura 8 - Média (1984 - 2005) da temperatura do ar observada (CRU) e simulada pelos modelos global (HadGEM2-ES) e regional (HadRM3P). As cores indicam o valor da temperatura em ${ }^{\circ} \mathrm{C}$. Os conjuntos de dados encontram-se em sua resolução horizontal original (lat/lon): $0,5^{\circ}$ (CRU), $1,25^{\circ} \times 1,875^{\circ}$ (HadGEM2-ES) e $0,22^{\circ}$ (HadRM3P). Médias de dezembro a fevereiro (DJF), março a maio (MAM), junho a agosto (JJA) e de setembro a outubro (SON). 


\subsubsection{AVALiAÇÃo do MOdelo CLIMÁtico REgional QUANTO À TEMPERATURA}

De modo análogo ao aplicado à precipitação, também foi avaliado o desempenho do modelo regional em simular o clima atual (1981 a 2005) da temperatura do ar sobre a Amazônia oriental, a partir das análises dos mapas do viés, raiz do erro médio quadrático (REMQ) e da correlação entre as séries de dados simulado e observado.

Considera-se os valores absolutos entre \pm 2 como limiar indicativo de boa concordância do modelo com relação a observação, onde os valores positivos e negativos, maiores que este limiar, indicam superestimativa e subestimativa do modelo, respectivamente (DE SOUZA et al., 2016). A distribuição espacial do viés da temperatura na área de estudo pode ser vista na figura 09. Nela, observa-se que o HadRM3P subestima a temperatura de 2 a $4^{\circ} \mathrm{C}$ sobre faixa que se estende do sul ao nordeste da Amazônia oriental nos trimestres de DJF e MAM. Isto pode estar associado à inadequada parametrização dos processos de superfície e radiação do modelo. Por outro lado, o melhor desempenho do HadRM3P ocorre nos trimestres seguintes, destacando-se SON. Vale ressaltar um núcleo de temperatura subestimada em mais de $8^{\circ} \mathrm{C}$, localizado no oeste do Pará, o qual é persistente ao longo do ano. Tal inconsistência, pode estar relacionada a uma inadequada representação da vegetação pelo modelo regional nesta região, resultando em alto valor de albedo, levando a um resfriamento na superfície associado a redução da quantidade de radiação solar absorvida (ALVES E MARENGO, 2010).
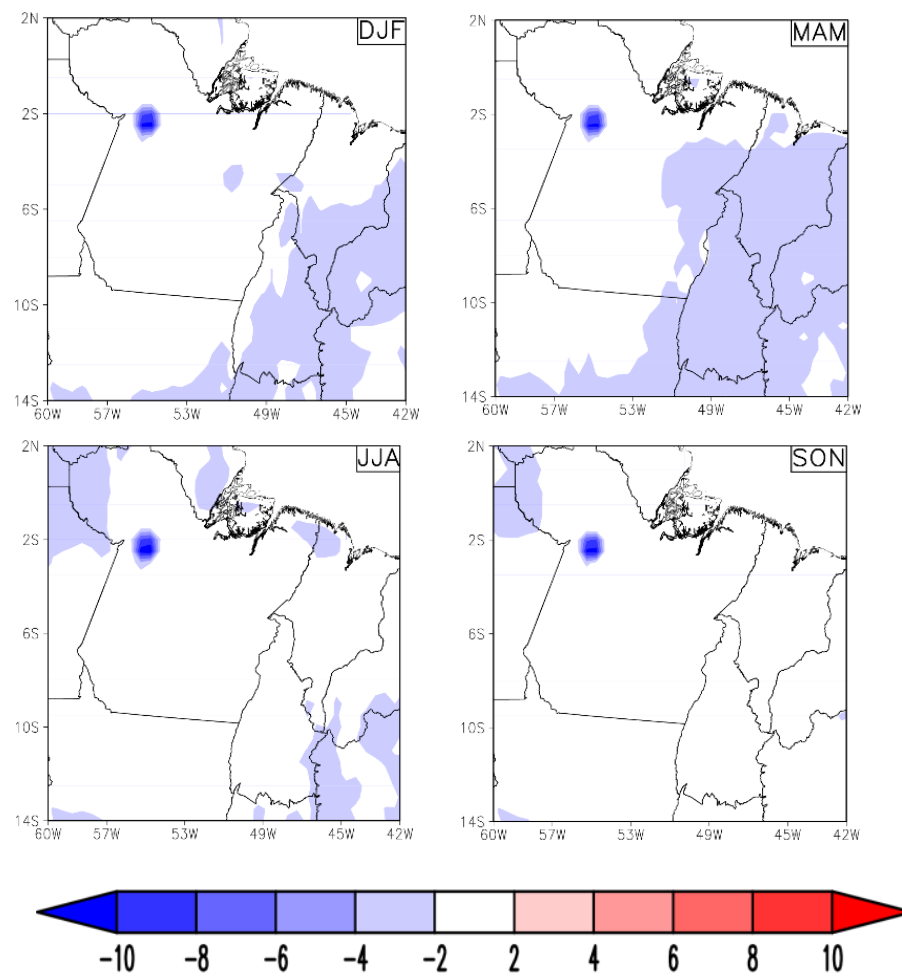

Figura 9 - Viés absoluto da temperatura do ar sazonal observada pelo CRU e a simulada pelo HadRM3P sobre a Amazônia Oriental. A escala de cores refere-se a diferença entre o 
simulado e o observado no período de 1981 a 2005, onde as cores em vermelho indicam valores positivos para viés (superestimativa) e as cores em azul, viés negativo (subestimativa). Ambos, CRU e HadRM3P, na resolução horizontal de 0,50 de lat/lon Unidade: ${ }^{\circ} \mathrm{C}$.

Analisou-se, também, a eficiência do modelo regional em simular temperatura sazonal no clima atual (1981-2005) sobre a Amazônia oriental. Para tanto, apresenta-se na Figura 10 a espacialização do parâmetro REQM (Raiz do Erro quadrático médio) em ${ }^{\circ} \mathrm{C} /$ dia. Nela, é possível verificar que nos trimestres de DJF e MAM, os erros de representação da temperatura pelo modelo regional ocorrem em uma faixa orientada de sul-nordeste na área de estudo, entre 2 e $4{ }^{\circ} \mathrm{C} /$ dia. Esta configuração está de acordo com o encontrado no viés (subestimativa, Fig. 9) e está relacionada à inadequada parametrização dos processos de superfície e radiação utilizada pelo modelo regional. Este, por outro lado, apresenta melhorias nas simulações da temperatura em JJA, atingindo melhor eficiência no trimestre de SON, exceto no extremo noroeste da região e em Santarém-PA.

A correlação temporal entre as séries de dados simulada e observada da temperatura também foi incluída nesta análise qualitativa (Figura 11). No trimestre de JJA e SON, onde ocorrem os menores erros do modelo quanto à variabilidade espacial da temperatura (Figuras 09 e 10), os mapas das correlações temporais mostram os maiores coeficientes positivos entre as séries de dados, destacando-se a faixa orientada no sentido sul-noroeste da região em JJA, com coeficientes entre 0,4 e 0,8. Para o trimestre DJF, destaca-se a alta correlação positiva $(0,6$ a 0,8$)$ na região litorânea entre os estados do Pará e Maranhão. Em termos gerais, o modelo regional apresenta um bom desempenho em capturar a variabilidade temporal da temperatura do ar no sul da Amazônia oriental, exceto em MAM, cujas maiores correlações positivas estão em grande parte confinadas no extremo sul da região. 

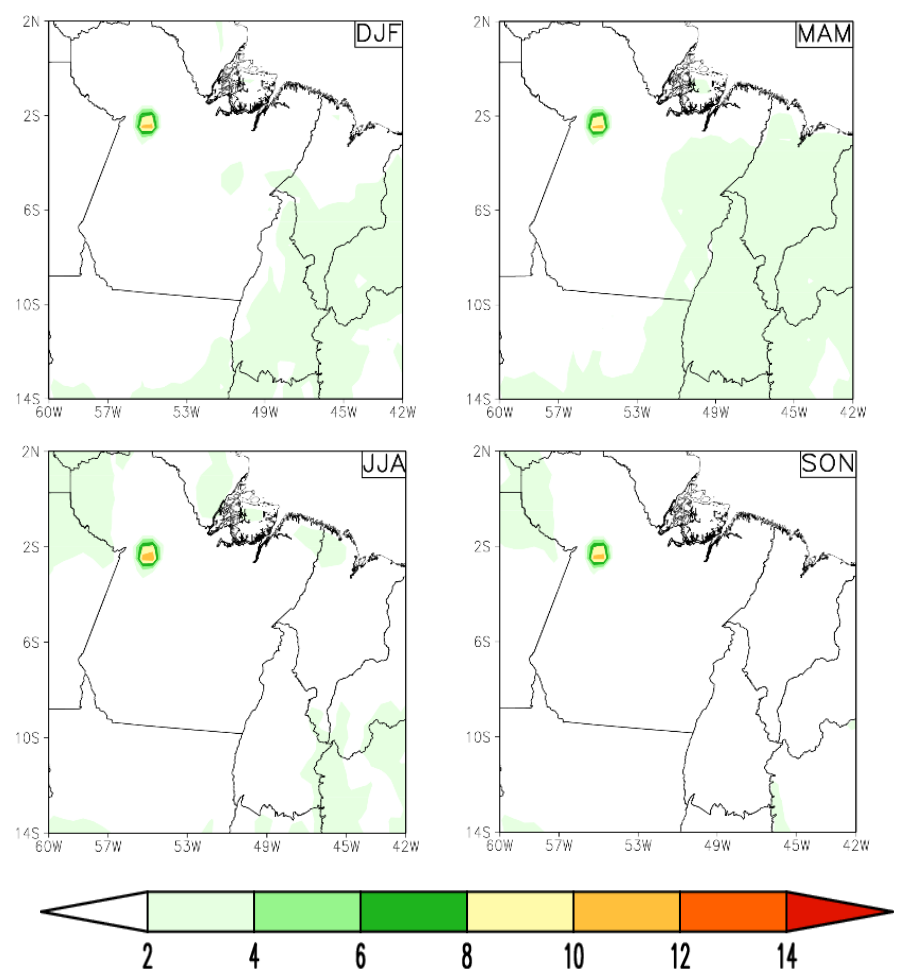

Figura 10 - Espacialização da Raiz do erro quadrático médio (REQM) entre a temperatura simulada (HadRM3P) e observada (CRU) na Amazônia Oriental no período de 1981 a 2005. A legenda em cores refere-se à acurácia do modelo. Ambos, CRU e HadRM3P, na resolução horizontal de $0,5^{\circ}$ de lat/lon. Unidade: ${ }^{\circ} \mathrm{C} . \mathrm{dia}^{-1}$. 

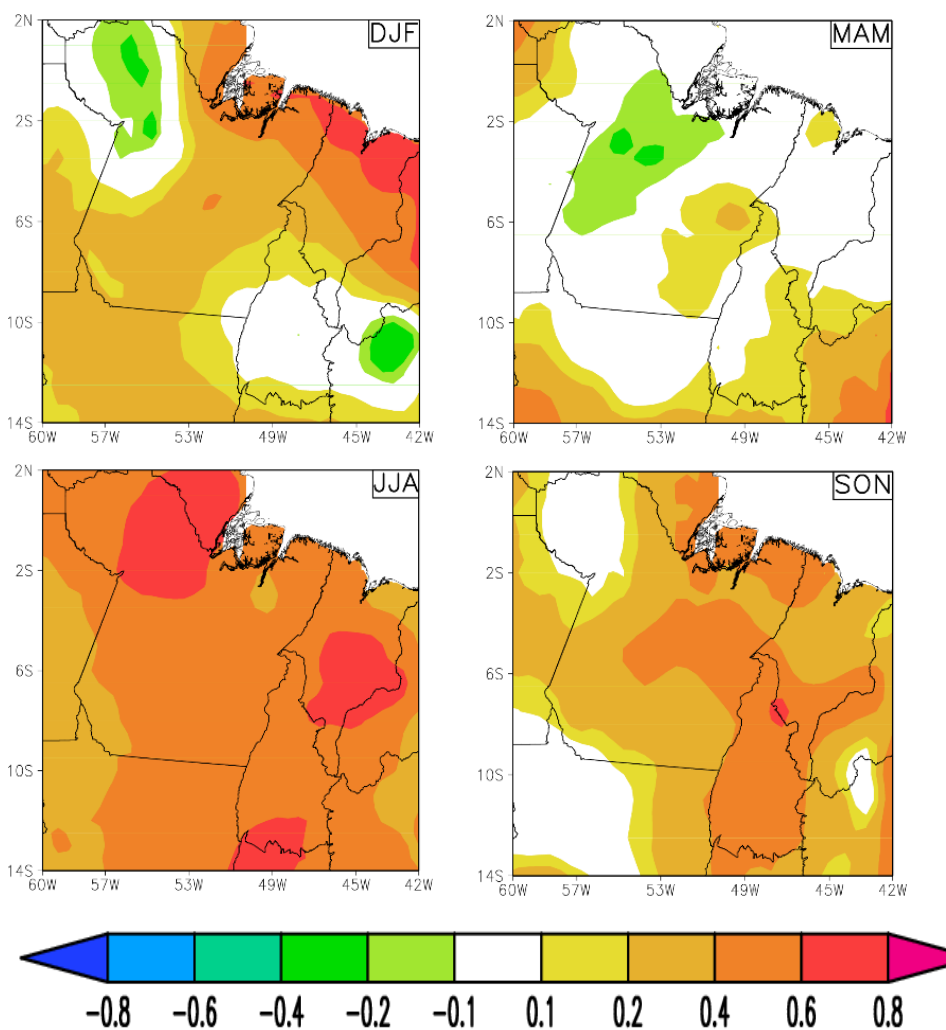

Figura 11 - Correlação temporal da temperatura do ar simulada (HadRM3P) e observada (CRU). Média do período de 1981 a 2005. A escala de cores refere-se ao coeficiente de correlação entre as séries. Ambos, CPC e HadRM3P, na resolução horizontal de 0,50 de lat/lon. Unidade: Adimensional.

A Figura 12 mostra o ciclo anual da temperatura do ar observada (CRU) e simulada (HadGEM2-ES e HadRM3P) sobre as sub-regiões na Amazônia oriental, no período de 1984 a 2005. Nela, nota-se que a temperatura média observada nas áreas em estudo apresenta pequena variação ao longo do ano, associado aos altos valores de umidade relativa do ar e energia solar incidente na superfície (MARENGO E NOBRE, 2009). Os modelos, por sua vez, mostram maior amplitude anual da temperatura $\left(>3^{\circ} \mathrm{C}\right)$ em relação ao observado $\left(<2^{\circ} \mathrm{C}\right)$, sendo menor em R1 (Fig. 12b), onde o CRU apresenta oscilação da temperatura entre $26,5^{\circ}$ a $27,9^{\circ} \mathrm{C}$ ao longo do ano, enquanto para os modelos, global e regional, essa variabilidade fica entre $25,4^{\circ}-28,9^{\circ} \mathrm{C}$ e $25^{\circ}-28^{\circ} \mathrm{C}$, respectivamente. De forma mais detalhada, pode-se perceber que em R1 (Figura 12a), apesar de subestimar a temperatura de dezembro a junho, o modelo global apresenta melhor desempenho que o regional. Este último, por sua vez, apresenta ganho sobre o global de julho a novembro (subestimativa) quando comparado à observação.

Na sub-região 2 (R2, Fig. 12b), ambos os modelos não foram capazes de simular a magnitude da temperatura. No entanto, conseguem identificar o aumento gradual da temperatura, errando, somente, o mês em que é observado o maior valor desta variável, passando de setembro para outubro. Neste contexto, mesmo que subestimando a temperatura, o modelo global apresenta desempenho um pouco melhorado ao modelo regional, no período de dezembro 
a abril, no entanto, de maio a agosto, há um ganho em se utilizar o regional sobre o global.

Já em R3 (Fig. 12c) é observada maior variabilidade da temperatura ao longo do ciclo anual, quando comparada a R1 e R2. Isto pode estar associado à sua localização mais sul em relação às demais sub-regiões, estando, também, sujeita a influência de sistemas frontais que avançam mais ao norte do País (BRINKMAN E RIBEIRO, 1972; MARENGO et al., 1996). Além disso, outro fator importante pode ser levado em consideração: o relevo, visto que nesta região há a presença de vales e pequenas formações rochosas (não mostrado). Quanto às simulações, em termos gerais, o modelo global apresenta melhor desempenho que o regional de janeiro a abril, contudo, nos demais meses, há um ganho em se utilizar o modelo regional. Além disso, este último, foi capaz de identificar o mês onde é observado o maior valor da temperatura na região (setembro), porém superestima sua magnitude em $1^{\circ} \mathrm{C}$ em relação ao observado pelo CRU.

A subestimativa da precipitação para a Amazônia oriental (Figs. 4 e 7) revela a deficiência do modelo regional em simular quantidade menor de umidade atmosférica, que por sua vez contribui para uma maior amplitude térmica, como demostrado pelos modelos na Figura 12 . O mesmo raciocínio, também, é notado nas regiões $\mathrm{R} 2$ e R3, cuja variabilidade mensal da temperatura média simulada pelos modelos é maior quando comparada à observação.

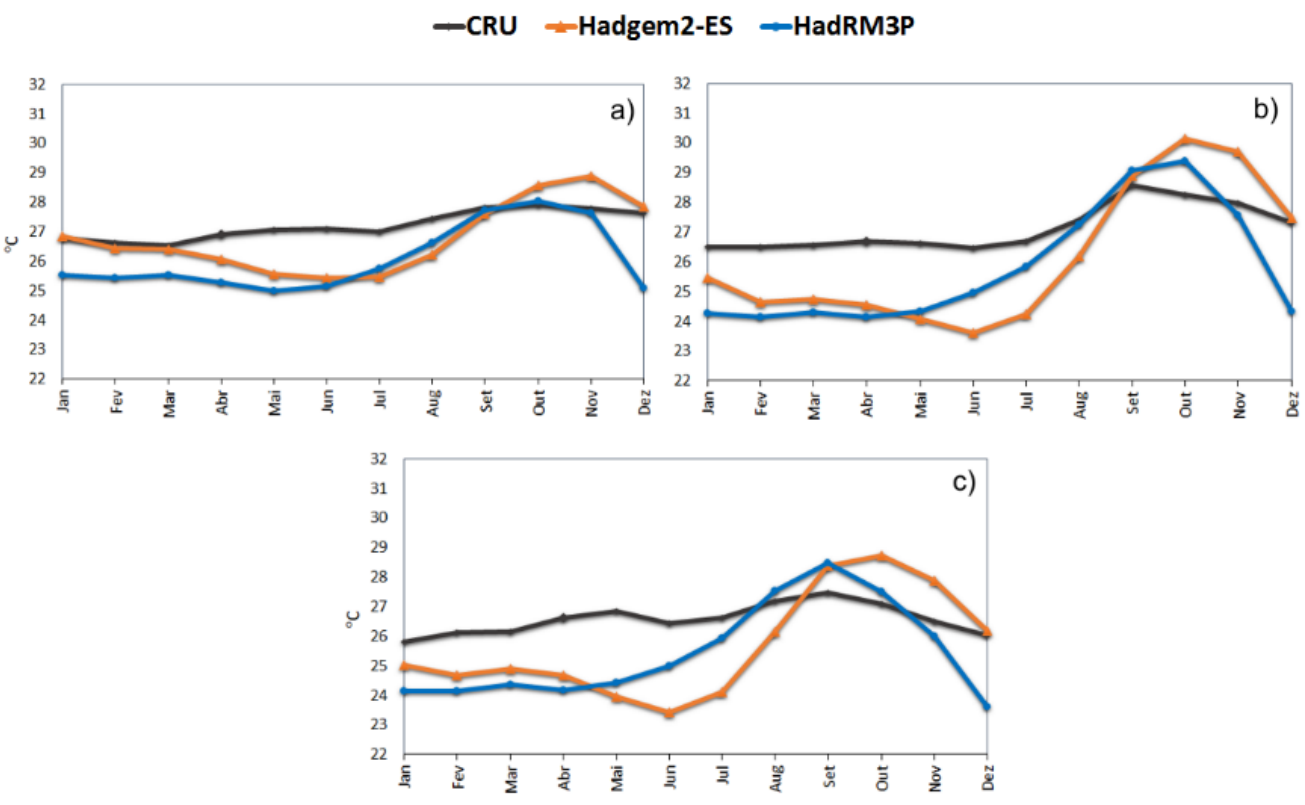

Figura 12 - Ciclo anual médio (1984 - 2005) da temperatura do ar $\left({ }^{\circ} \mathrm{C}\right)$ simulada pelo modelo global (HadGEM2-ES) e regional (HadRM3P), e observada (CRU) nas sub-regiões de estudo (a) R1, (b) R2 e (c) R3. A linha preta representa a observação, a laranja o modelo global e a linha azul, o modelo regional. Cada um em sua resolução horizontal (lat/lon) original: $0,5^{\circ} \times 0,5^{\circ}$ (CRU), $1,25^{\circ} \times 1,875^{\circ}$ (HadGEM2-ES) e $0,22^{\circ} \times 0,22^{\circ}$ (HadRM3P). 
Os escores estatísticos da temperatura sazonal simulada (HadRM3P) e observada (CRU) nas sub-regiões de estudo são mostrados na tabela 3, onde observa-se que ao longo do ano, em R1, o modelo regional subestima a temperatura em todas as sub-regiões, sendo de menor magnitude no trimestre do $\operatorname{SON}\left(0,1^{\circ} \mathrm{C}\right)$. Além disso, mostra melhor desempenho em capturar a variabilidade da temperatura neste período, com desvios em torno da média de $0,5^{\circ} \mathrm{C}$. Em R2, na primavera austral (SON), o modelo regional superestima em apenas $0,2^{\circ} \mathrm{C}$ a temperatura média, porém não é capaz de capturar a variabilidade regional. O melhor desempenho ocorre nos trimestres de DJF e MAM, onde a diferença entre os desvios padrões das séries é de $0,1^{\circ} \mathrm{C}$. Comportamento similar também pode ser observado nas estatísticas para a região R3. Em geral, os maiores vieses ocorrem em R2 e R3 nos trimestres de DJF e MAM, subestimando a temperatura em mais de $2^{\circ} \mathrm{C}$. Neste contexto, apesar do modelo regional subestimar as temperaturas, a variabilidade em torno da própria média das séries é bem próxima (diferença entre os desvios das séries igual a $0,1^{\circ} \mathrm{C}$ ). Enquanto que, os menores vieses são percebidos no trimestre de SON em todas as sub-regiões, entretanto a diferença entre os desvios das séries de dados observados e simulados são grandes, acima de $0,2^{\circ} \mathrm{C}$, exceto em $\mathrm{R} 1$, onde o modelo regional mostrou-se capaz de simular a variabilidade em torno da média da temperatura, com desvios das séries igual a $0,5^{\circ} \mathrm{C}$. 
Tabela 3 - Escores estatísticos entre a temperatura do ar sazonal observada (CRU) e a simulada (HadRM3P) para o período de 1981 a 2005 nas sub-regiões de estudo R1, R2 e R3. Viés refere-se a diferença entre a média da simulação e a média da observação, STDEV é o desvio padrão da série. Os resultados são apresentados em médias trimestrais: Dezembro, Janeiro e Fevereiro (DJF), Março, Abril e Maio (MAM), Junho, Julho e Agosto (JJA), Setembro, Outubro e Novembro (SON). Ambos, CRU e HadRM3P, na resolução horizontal de $0,5^{\circ}$ de lat/lon.

\begin{tabular}{|c|c|c|c|c|c|c|c|c|c|}
\hline \multirow[b]{2}{*}{ DJF } & \multicolumn{3}{|c|}{$R 1$} & \multicolumn{3}{|c|}{$R 2$} & \multicolumn{3}{|c|}{$R 3$} \\
\hline & Viés & STDEV & Media & Viés & STDEV & Media & Viés & STDEV & Media \\
\hline $\begin{array}{l}\text { Simulado } \\
\text { (HadRM3P) }\end{array}$ & \multirow{2}{*}{$-1,3$} & 0,5 & 25,7 & \multirow{2}{*}{$-2,2$} & 0,5 & 24,5 & \multirow{2}{*}{$-2,0$} & 0,4 & 24,3 \\
\hline $\begin{array}{l}\text { Observado } \\
\text { (CRU) }\end{array}$ & & 0,4 & 27,0 & & 0,4 & 26,7 & & 0,5 & 26,3 \\
\hline \multicolumn{10}{|l|}{ MAM } \\
\hline $\begin{array}{c}\text { Simulado } \\
\text { (HadRM3P) }\end{array}$ & \multirow{2}{*}{$-1,6$} & 0,4 & 25,2 & \multirow{2}{*}{$-2,4$} & 0,4 & 24,1 & \multirow[b]{2}{*}{$-2,6$} & 0,5 & 24,2 \\
\hline $\begin{array}{l}\text { Observado } \\
\text { (CRU) } \\
\text { JJA }\end{array}$ & & 0,5 & 26,8 & & 0,5 & 26,6 & & 0,5 & 26,8 \\
\hline $\begin{array}{c}\text { Simulado } \\
\text { (HadRM3P) }\end{array}$ & & 0,5 & 25,7 & & 0,7 & 25,8 & & 0,7 & 25,9 \\
\hline $\begin{array}{l}\text { Observado } \\
\text { (CRU) }\end{array}$ & $-1,4$ & 0,4 & 27,1 & $-1,0$ & 0,5 & 26,8 & $-1,0$ & 0,6 & 26,9 \\
\hline \multicolumn{10}{|l|}{ SON } \\
\hline $\begin{array}{l}\text { Simulado } \\
\text { (HadRM3P) }\end{array}$ & \multirow{2}{*}{$-0,1$} & 0,5 & 27,6 & \multirow{2}{*}{0,2} & 0,9 & 28,3 & \multirow{2}{*}{0,1} & 0,9 & 27,3 \\
\hline $\begin{array}{l}\text { Observado } \\
\text { (CRU) }\end{array}$ & & 0,5 & 27,7 & & 0,5 & 28,1 & & 0,7 & 27,2 \\
\hline
\end{tabular}

\section{CONCLUSÕES}

O presente trabalho contribui cientificamente aos estudos de modelagem regional na Amazônia oriental, ao avaliar a evolução do sistema de modelagem climática PRECIS, em reproduzir a precipitação e a temperatura do ar no clima atual (1981 a 2005), tomando-se como referência observações provenientes do CPC (precipitação) e CRU (temperatura). A partir destas análises, foram obtidas as seguintes conclusões relevantes:

O ganho em se utilizar um modelo regional (HadRM3P) aninhado a um modelo global (hadGEM2-ES) nos estudos de clima regional demonstrou que a utilização do modelo regional resultou em melhorias na simulação de padrões espaciais de precipitação e temperatura com relação às observações, contudo muitos erros sistemáticos do modelo global permaneceram na simulação final.

A avaliação do desempenho do modelo em simular a precipitação e a temperatura no clima atual (1981 a 2005) sobre a Amazônia oriental mostrou que:

O modelo subestima a precipitação na estação chuvosa da região (Dezembro a Maio), principalmente no trimestre de MAM, associado à presença da Zona de Convergência Intertropical. Tal comportamento é ratificado na 
eficiência do modelo (REMQ), porém apresenta melhor desempenho (menores erros) no trimestre de JJA. Apesar dos erros sistemáticos quanto à distribuição da precipitação na Amazônia oriental, o campo de correlações revelou uniformidade temporal entre as séries de dados, com valores positivos, destacando-se a porção sul da região em MAM $(>0,4)$ e em SON $(>0,6)$; Raiz do Erro Médio Quadrático (REMQ).

Com relação à temperatura, os maiores vieses e, consequentemente, menor eficiência do modelo regional ocorrem nos trimestres de DJF e MAM no leste da Amazônia oriental, e se mantêm ao longo do ano sobre parte do oeste do Pará. Todavia, em termos gerais, o modelo regional mostrou bom desempenho em capturar a variabilidade temporal da temperatura em JJA e SON.

Os escores estatísticos (viés, desvio padrão e média) entre as séries de dados simulados pelo HadRM3P e o observado (CPC e CRU) nas três sub-regiões na Amazônia oriental revelaram que o modelo regional apresentou melhor acurácia em simular a precipitação no trimestre de JJA, apresentando viés, desvios e média semelhantes ou bem próximos ao observado, destacando-se R3. Quanto à temperatura do ar, o modelo regional alcançou melhores resultados no trimestre de SON, principalmente em $\mathrm{R} 1$, onde apesar de ocorrer subestimativa desta variável a magnitude dele é menor, porém com mesmo desvio e média da série observada.

Quanto ao ciclo anual, os modelos apresentaram bom e regular desempenho em reproduzir a precipitação e temperatura nas sub-regiões da Amazônia oriental, respectivamente. Contudo, há um ganho em se utilizar o modelo regional em relação ao global (HadGEM2-ES), principalmente na estação seca. Além do mais, com relação à temperatura, tanto o Hadgem2-ES quanto HadRM3P tendem a amplificar/acentuar as características do ciclo anual desta variável.

Na avaliação comparativa, as discrepâncias entre a simulação e a observação, designados como erros sistemáticos do modelo, deve-se, também, levar em conta a escassez de observações na Amazônia e que posteriormente são interpoladas. Essa característica pode limitar a confiabilidade da estimativa de erro (CHOU et al., 2014).

Os resultados apresentados revelaram que são necessárias alterações nas parametrizações do modelo regional HadRM3P, a fim de obter melhorias nas simulações da precipitação e temperatura na Amazônia oriental. Entretanto, não desqualificam o modelo a ser utilizado em simulações do clima futuro, visto que a acurácia dos modelos numéricos quanto à distribuição e magnitude da precipitação, por exemplo, ainda apresentam limitações (AMBRIZZI et al., 2007).

\section{AGRADECIMENTOS}

O Primeiro autor agradece ao CNPq (processo no 300481/2017-9) pelo apoio financeiro. Ao Dr. Lincoln Alves (CCST/INPE) pela disponibilização dos dados dos modelos utilizados neste trabalho, bem como sua intermediação junto ao Met Office Hadley Centre (Inglaterra), desenvolvedor dos modelos avaliados neste artigo. 


\section{REFERÊNCIAS BIBLIOGRÁFICAS}

ADAMS, D. K.; SOUZA, E. P.; COSTA, A. A. Convecção úmida na Amazônia: implicações para modelagem numérica. Revista Brasileira de Meteorologia, $v$. 24, n. 2, p. 168-178, 2009.

ALVES, L. M. Simulações da variabilidade do clima presente sobre a América do Sul utilizando um modelo climático regional. Tese de Doutorado, Instituto Nacional de Pesquisas Espaciais-INPE, São José dos Campos-SP, 92 pp. 2007. Disponível em < http://mtc-m16b.sid.inpe.br/col/sid.inpe.br/mtcm17@80/2007/06.13.12.59/doc/publicacao.pdf> Acesso em 7 de fevereiro de 2017.

ALVES, L. M. e MARENGO, J. A. Assessment of regional seasonal predictability using the PRECIS regional climate modeling system over South America. Theoretical and Applied Climatology, v. 100, p. 337-350, 2010.

AMBRIZZI, T. et al. Cenários regionalizados de clima no Brasil para o Século XXI: Projeções de clima usando três modelos regionais. Relatório3, Ministério do Meio Ambiente-MMA, Brasília, 108 p., 2007.

AMORIM NETO, A. C. Estrutura e evolução de frentes frias intensas na Região Amazônica brasileira. Tese de Doutorado em Clima e Ambiente. Instituto Nacional de Pesquisas da Amazônia, Manaus-AM, 182 pp. 2013. Disponível em http://bdtd.inpa.gov.br/bitstream/tede/1513/2/Tese_Alcides\%20de\%20Castro \%20Amorim\%20Neto.pdf>. Acesso em: 12 de novembro de 2017.

BRINKMAN, W. L. F. e RIBEIRO, M. N. G. Air temperatures in Central Amazônia. III Vertical temperature distribuition on a clearcut area and in a secondary forest near Manaus (cold front conditions July 10th 1969). Acta amazônica, 2(3), p. 25 - 29, 1972.

CAESAR, J. et al. Response of the HadGEM2 earth system model to future greenhouse gas emissions pathways to the year 2300. Journal of Climate v. 26, p. 3275-3284, 2013. Doi: 10.1175/JCLI-D-12-00577.1.

CAVALCANTI, I. et al. Global climatological features in a simulation using the CPTEC/COLA AGCM. Journal of Climate, v. 15, p. 2965-2988, 2002.

$\mathrm{CHOU}, \mathrm{S}$. et al. Evaluation of the Eta Simulations Nested in Three Global Climate Models. American Journal of Climate Change, v. 3, p. 438-454, 2014.

COHEN, J. C. P.; SILVA DIAS, M. A. F.; NOBRE, C. Enviromental conditions associated with amazonian squall lines: A case study. Monthly Weather Review, v. 123, p. 3163-3174, 1995.

COLLINS, W. J. et al. Development and evaluation of an Earth-System model HadGEM2, Geoscientific Model Development, v. 4, p. 1051-1075, 2011.

DE SOUZA CUSTODIO, $M$. et al. Impact of increased horizontal resolution in coupled and atmosphere-only models of the HadGEM1 family upon the climate patterns of South America. Climate Dynamics, v. 47, p. 1 - 24, 2016.

DE SOUZA, E.B.; KAYANO, M.T.; AMBRIZZI, T. The regional precipitation over the eastern Amazon/northeast Brazil modulated by tropical Pacific and Atlantic SST anomalies on weekly timescale. Revista Brasileira de Meteorologia, v. 19, n. 2, p. 113-122, 2004. 
DE SOUZA, E. B.; ROCHA, E. J. P. Diurnal variations of rainfall in Bragança-PA (eastern Amazon) during rainy season: mean characteristics and extreme events. Revista Brasileira de Meteorologia, v. 21, n. 3, p. 142-152, 2006.

DE SOUZA, E. B. et al. Precipitação sazonal sobre a Amazônia oriental no período chuvoso: observações e simulações regionais com o RegCM3. Revista Brasileira de Meteorologia, 24(2), p. 111-124, 2009. https://dx.doi.org/10.1590/S0102-77862009000200001.

DE SOUZA, E. B. et al. Sazonalidade da precipitação sobre a Amazônia legal brasileira: clima atual e projeções futuras usando o modelo regcm4. Revista Brasileira de Climatologia, v. 18, 2016.

ESSERY, R. L. H. et al. Explicit Representation of Subgrid Heterogeneity in a GCM Land Surface Scheme. Journal of Hydrometeorology, v. 4, p. 530-543, 2003.

FIGUEROA, S. N. E NOBRE, C. A. Precipitation distribution over central and western tropical South America. Climanálise, v. 6, p. 36-40, 1990.

FLATO, G. et al. Evaluation of climate models. In Climate Change 2013: The Physical Science Basis. Contribution of Working Group I to the Fifth Assessment Report of the Intergovernmental Panel on Climate Change. Cambridge University Press, Cambridge, United Kingdom and New York, NY, USA, 2013.

GIORGI, F. et al. Regional Climate Information: Evaluation and Projections (Chapter 10). In Climate Change 2001: The Scientific Basis, Contribution of Working 32 Group I to the Third Assessment Report of the IPCC [Houghton, ]. T., Y. Ding, D. J. Griggs, M. Noguer, P. J. van der Linden, X. Dai, K. Maskell, and C. A. Johnson (eds.)]. Cambridge U. Press: Cambridge, p. 739-768, 2001.

GORDON, N.; SHAYKEWICH, J. Guidelines on performance assessment of public weather services. WMO/TD, n. 1023, 32 pp, 2000.

GRECO, S. et al. Rainfall and surface kinematic conditions over central Amazonia during ABLE 2B, Journal of Geophysical Research, v. 95(D10), p. 17001-17014, 1990.

HARRIS, I.; JONES, P. D.; OSBORN, T. J.; LISTER, D. H. Updated highresolution grids of monthly climatic observations - the CRU TS3.10 Dataset. International Journal of Climatology, v. 34, p. 623-642, 2014.

HEWITSON, B. C.; CRANE, R. G. Consensus between GCM climate change projections with empirical downscaling: precipitation downscaling over South Africa. International Journal Climatology, v. 26, p. 1315-1337, 2006.

JONES, R.; NOGUER, M.; HASSELL, D.; HUDSON, D. Generating high resolution climate change scenarios using PRECIS. 2004 [disponível online em: http://www.metoffice.gov.uk/media/pdf/6/5/PRECIS_Handbook.pdf]. Acesso em 15 mar 2016.

KOUSKY, V. E. Pentad Outgoing Longwave Radiation Climatology for the South American Sector. Revista Brasileira de Meteorologia, v. 3, n. 1, p. 217-231, 1988.

LI, S.; MOTE, P. W. et al. Evaluation of a Regional Climate Modeling Effort for the Western United States Using a Superensemble from Weather@ home. Journal of Climate, v. 28(19), p. 7470-7488, 2015. 
LIMA, J. P. R.; ALVES, J. M. B. Um estudo de downscaling dinâmico de precipitação intrasazonal acoplado a modelo chuva-vazão na bacia hidrográfica alto-médio São Francisco. Revista Brasileira de Meteorologia, v. 24, n. 3, p. 323-338, 2009.

$\mathrm{LOH}, \mathrm{J}$. L. et al. Projected rainfall and temperature changes over Malaysia at the end of the 21st century based on PRECIS modelling system. Asia-Pacific Journal of Atmospheric Sciences, V. 52 (2), p. 191-208, 2016.

MATHISON, C. et al. Regional projections of North Indian climate for adaptation studies. Science Total Environment, 2013. DOI: http://dx.doi.org/10.1016/j.scitotenv.2012.04.066.

MARENGO, J. A.; NOBRE, C. A.; CULF, A. D. Climatic Impacts of "Friagens" in Forested and Deforested Areas of the Amazon Basin. Journal of Applied Meteorology, v. 36, p. 1553-1566, 1997.

MARENGO, J. A. et al. Onset and end of the rainy season in the Brazilian Amazon Basin. Journal of Climate, v. 14, p. 833-852, 2001.

MARENGO, J. et al. Assessment of regional seasonal rainfall predictability using the CPTEC/COLA atmospheric GCM. Climate Dynamics, v. 21, p. 459-475, 2003.

MARENGO, J. A.; NOBRE, C. A. Tempo e Clima no Brasil: Clima da Região Amazônica. $1^{a}$ Edição. São Paulo: Oficina de textos, 2009.

MARENGO, J. A.; ESPINOZA, J. C. Extreme Seasonal Droughts and Floods in Amazonia: Causes, Trends and Impacts. International Journal of Climatology, $v$. 36, p. 1033-1055, 2015.

MEEHL, G. et al. The WCRP CMIP3 Multimodel data set. A new era in climate change research. Bulletin of the American Meteorological Society, v. 88, p 13831394, 2007. DOI:10.1175/BAMS-88-9-1383.

MENDES, D.; MARENGO, J. Temporal downscaling: a comparison between artificial neural network and autocorrelation techniques over the Amazon Basin in presente and future climate change scenarios. Theoretical and Applied Climatology.2009. Doi:10.1007/s00704-009-0193-y.

NOBRE, C. A.; OBREGÓN, G.O.; MARENGO, J. A.; FU R.; POVEDA G. Características do clima amazônico: Aspectos principais. Geophysical Monography Series, v. 186, p. 149-162. 2010.

OLIVEIRA, P. J. de et al. Efeitos de um evento de friagem nas condições meteorológicas na Amazônia: um estudo de caso. Acta amazônica, v. 34, n. 4, p. 613-619, 2004.

OYAMA, D. M. Erros sistemáticos no clima da região tropical da América do Sul simulado pelo modelo regional MM5 em baixa resolução horizontal. Revista Brasileira de Meteorologia, v. 21, n. 1, p. 118-133, 2006.

PBMC - Painel Brasileiro de Mudanças Climáticas. Sumário Executivo - Base Científica das Mudanças Climáticas. Contribuição do Grupo de Trabalho 1 ao Primeiro Relatório de Avaliação Nacional do Painel Brasileiro de Mudanças Climáticas. PBMC, Rio de Janeiro, v. 1, 24 p, 2013.

RICARTE, R. M. D.; HERDIES, D. L.; BARBOSA, T. F. Patterns of atmospheric circulation associated with cold outbreaks in southern amazonia. Meteorological Applications, v. 22, p. 129-140, 2015. 
SALATHE, E. P. Comparison of Various Precipitation Downscaling Methods for the Simulation of Streamflow in a Rainshadow River Basin. International Journal of Climatology, v. 23, p. 887-901, 2003.

SALATHÉ, E. P.; STEED, R.; MASS, C. F.; ZAHN, P. A high-resolution climate model for the U.S. Pacific Northwest: mesoscale feedbacks and local responses to climate change. Journal of Climate, v. 21, p. 5708-5726, 2008.

SILVA DIAS, M. A. F.; ROZANTE, J. R.; MACHADO, L. A. T. Tempo e Clima no Brasil: Complexos convectivos de mesoescala na América do Sul. $1^{a}$ Edição. São Paulo: Oficina de textos, 2009.

SIMON W. et al. Technical Manual for PRECIS The Met Office Hadley Centre regional climate modelling system Version 2.0.0 www.metoffice.gov.uk/precis 2015.

SOUZA, S. S. Impactos Climáticos Regionais da Mudança de Vegetação no Semiárido do Nordeste Brasileiro. Tese de Doutorado. Instituto Nacional de Pesquisas Espaciais, São José dos Campos-SP, 209 pp. 2006. Disponível em: <http://urlib.net/sid.inpe.br/MTC-m13@80/2006/06.12.13.47 > Acesso em: 20 out. 2017.

TANAJURA, C. A. S.; GENZ, F.; ARAUJO, H. Mudanças climáticas e recursos hídricos na Bahia: validação da simulação do clima presente do HadRM3P e comparação com os cenários A2 e B2 para 2070-2100. Revista Brasileira de Meteorologia, v. 3, p. 345-58, 2010.

TIMBAL, B.; FERNANDEZ, E.; LI, Z. Generalization of a statistical downscaling model to provide local climate change projections for Australia. Environmental Modeling, v. 24 (03), p. 341-358, 2009.

VALVERDE, M. C.; MARENGO, J. A. Mudanças na circulação atmosférica sobre a América do Sul para cenários futuros de clima projetados pelos modelos globais do IPCC AR4. Revista Brasileira de Meteorologia, São Paulo, v. 25, n. 1, p. 125$145,2010$.

VERA. C. et al. Towards a Unified View of the American Monsoon Systems. Journal of Climate, v. 19, p. 4977-5000, 2006.

WEICHERT, A; BURGER, G. Linear versus nonlinear techniques in downscaling. Climate Research, v. 10, p. 83-93, 1998.

WILBY, R. L.; WIGLEY, T. M. L. Downscaling general circulation model output: a review of methods and limitations. Progress in Physical Geography v. 21, p. 530-548, 1997.

ZHANG, Y. et al. A future climate scenario of regional changes in extreme climate events over China using the PRECIS climate model. Geophysical Research Letters, v. 33: L24702, 2006. Doi:10.1029/2006GL027229.

ZHOU J. e LAU, K-M. Does a monsoon climate exist over South America? Journal of Climate, v. 11, p. 1020-1040, 1998. 